\title{
A quantitative test of infrared optical constants for supercooled sulphuric and nitric acid droplet aerosols
}

\author{
R. Wagner ${ }^{1}$, A. Mangold ${ }^{2}$, O. Möhler ${ }^{1}$, H. Saathoff ${ }^{1}$, M. Schnaiter ${ }^{1}$, and U. Schurath ${ }^{1}$ \\ ${ }^{1}$ Forschungszentrum Karlsruhe, Institute of Meteorology and Climate Research, Karlsruhe, Germany \\ ${ }^{2}$ Forschungszentrum Jülich, Institute of Chemistry and Dynamics of the Geosphere I (ICG-I): Stratosphere, Jülich, Germany
}

Received: 18 March 2003 - Published in Atmos. Chem. Phys. Discuss.: 8 May 2003

Revised: 23 July 2003 - Accepted: 28 July 2003 - Published: 8 August 2003

\begin{abstract}
In situ Fourier transform infrared (FTIR) extinction spectra of supercooled $\mathrm{H}_{2} \mathrm{SO}_{4} / \mathrm{H}_{2} \mathrm{O}$ and $\mathrm{HNO}_{3} / \mathrm{H}_{2} \mathrm{O}$ solution droplets were recorded in the large coolable aerosol chamber AIDA (Aerosol Interactions and Dynamics in the Atmosphere) of Forschungszentrum Karlsruhe for a range of aerosol compositions and at temperatures extending down to $192 \mathrm{~K}$. The measured spectra were quantitatively analysed in terms of aerosol composition and mass concentration by using Mie theory in combination with published refractive index data as input parameters. Simultaneously, total sulphuric acid and nitric acid mass concentrations from filter analysis and total water concentrations measured with the Lyman- $\alpha$ hygrometer of Forschungszentrum Jülich were used to calculate the aerosol composition at thermodynamic equilibrium inside the aerosol chamber. By comparing these measured aerosol parameters with those retrieved from the analysis of the FTIR spectra, the accuracy of the literature data sets of refractive indices could be assessed. In summary, four data sets were tested in the $\mathrm{H}_{2} \mathrm{SO}_{4} / \mathrm{H}_{2} \mathrm{O}$ system as well as two data sets in the $\mathrm{HNO}_{3} / \mathrm{H}_{2} \mathrm{O}$ system, partly revealing significant discrepancies in the retrieved aerosol properties. Potential explanations for these differences are discussed in this paper.
\end{abstract}

\section{Introduction}

Mid infrared remote sensing instruments are becoming a valuable tool to derive chemical composition, phase, volume, and size distribution parameters of stratospheric sulphuric acid aerosols and polar stratospheric clouds (PSCs). Mid infrared spectra can be obtained from ground-based, balloon, aircraft, and satellite experiments. Examples for these types of instruments include the Improved Stratospheric and Mesospheric Sounder (ISAMS) (Grainger et al., 1993), the

Correspondence to: R. Wagner (robert.wagner@imk.fzk.de)
Atmospheric Trace Molecule Spectroscopy (ATMOS) experiment (Eldering et al., 2001), the Improved Limb Atmospheric Spectrometer (ILAS) (Sasano et al., 1999), and the Michelson Interferometer for Passive Atmospheric Sounding - Balloon borne (MIPAS-B), aircraft-borne (MIPAS-STR), and satellite-borne (MIPAS-ENVISAT) versions (Echle et al., 1998; Höpfner et al., 2002; Höpfner, 2003).

The accurate retrieval of aerosol parameters depends on reliable optical constants, i.e. the real and imaginary parts of the complex refractive index. Recently, the data base of optical constants for binary sulphuric acid and nitric acid aerosols as well as ternary $\mathrm{H}_{2} \mathrm{SO}_{4} / \mathrm{H}_{2} \mathrm{O} / \mathrm{HNO}_{3}$ solution droplets (PSC - type $\mathrm{Ib}$ ) has been significantly improved owing to several extensive laboratory measurements which cover a wide range of aerosol compositions and temperatures. An extraordinary result of these studies was the strong temperature dependence of the optical constants due to temperature-dependent ion equilibria in the sulphuric and nitric acid systems. Tisdale et al. (1998) published the first data set of infrared optical constants of low-temperature sulphuric acid solutions between 45 and $80 \mathrm{wt} \% \mathrm{H}_{2} \mathrm{SO}_{4}$ at a temperature around $215 \mathrm{~K}$, noting that the change in optical constants with temperature would considerably influence the retrievals of aerosol mass concentrations and compositions from satellite measurements. While in this study the complex refractive indices were determined from FTIR transmission measurements through sulphuric acid films, Niedziela et al. (1999) and Norman et al. (1999) retrieved optical constants for the supercooled liquid $\mathrm{H}_{2} \mathrm{SO}_{4} / \mathrm{H}_{2} \mathrm{O}\left(32-87 \mathrm{wt} \% \mathrm{H}_{2} \mathrm{SO}_{4}\right.$, $200-300 \mathrm{~K})$ and $\mathrm{HNO}_{3} / \mathrm{H}_{2} \mathrm{O}\left(35-70 \mathrm{wt} \% \mathrm{HNO}_{3}, 220 \mathrm{~K}\right)$ systems directly from FTIR extinction spectra of laboratorygenerated aerosols in a flow cell. Water vapour in equilibrium with the aerosol was measured with a tuneable diode laser (TDL) system to calculate the aerosol composition using the thermodynamic model of Carslaw et al. (1995). Most recently, the authors succeeded in deriving the first infrared optical constants for supercooled ternary $\mathrm{H}_{2} \mathrm{SO}_{4} / \mathrm{H}_{2} \mathrm{O} / \mathrm{HNO}_{3}$ 

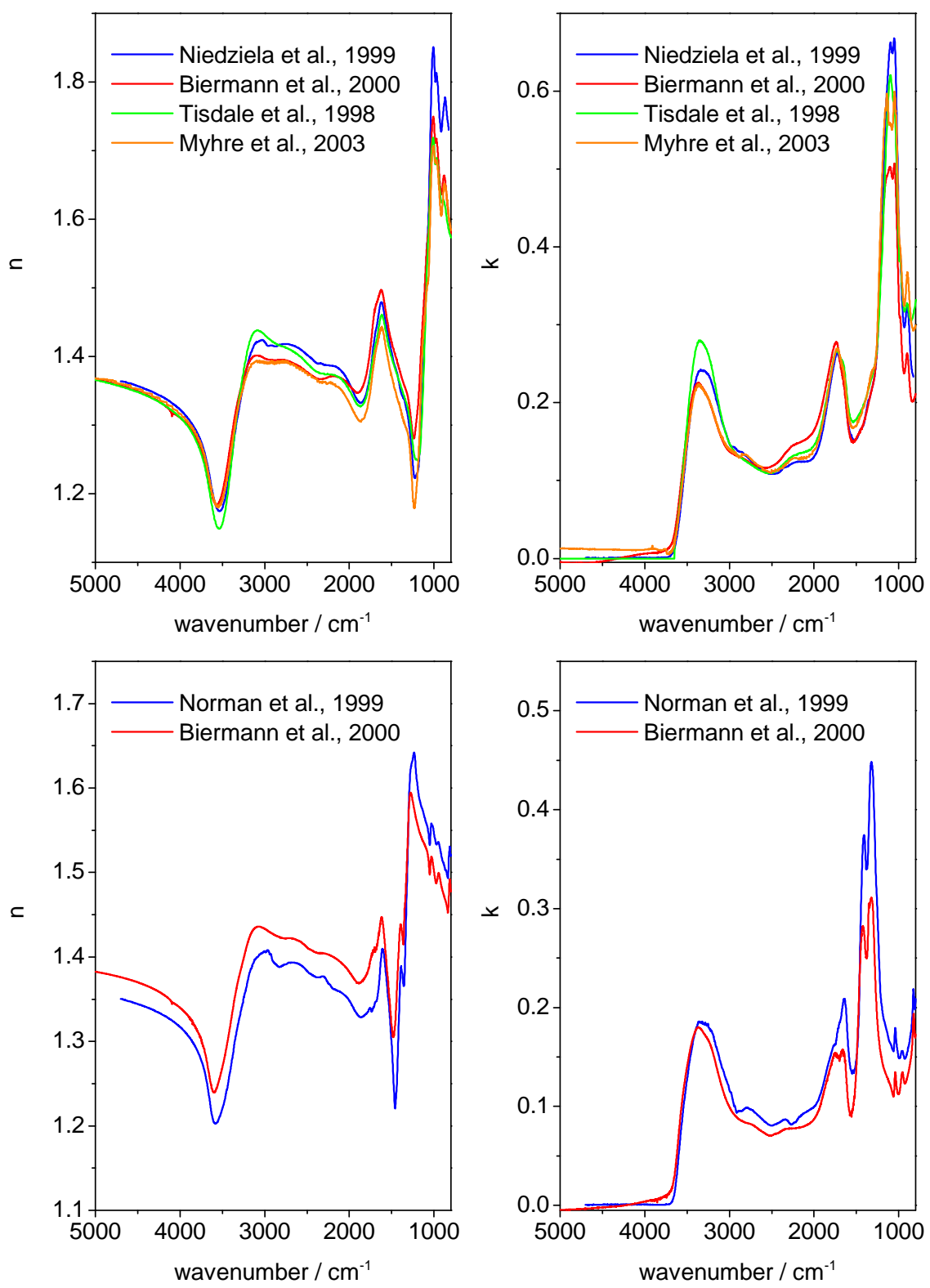

Fig. 1. Comparison of different data sets of optical constants for supercooled liquid $\mathrm{H}_{2} \mathrm{SO}_{4} / \mathrm{H}_{2} \mathrm{O}$ and $\mathrm{HNO}_{3} / \mathrm{H}_{2} \mathrm{O}$ available in the literature Upper panels: $45 \mathrm{wt} \% \mathrm{H}_{2} \mathrm{SO}_{4}, 215 \mathrm{~K}$; lower panels: $45 \mathrm{wt} \% \mathrm{HNO}_{3}, 220 \mathrm{~K}$.

solution droplets, however limited to a narrow range of compositions (Norman et al., 2002). Biermann et al. (2000) applied FTIR spectroscopy of thin films of aqueous sulphuric and nitric acid to derive optical constants in the composition and temperature range of $10-80 \mathrm{wt} \% \mathrm{H}_{2} \mathrm{SO}_{4}(183-293 \mathrm{~K})$ and $10-54 \mathrm{wt} \% \mathrm{HNO}_{3}(213-293 \mathrm{~K})$. Furthermore, the authors have proposed a mixing rule to calculate the complex refractive indices for the ternary solutions from the data sets of the two binary systems. Finally, Myhre et al. (2003) have derived complex refractive indices of 38-81 wt\% aqueous $\mathrm{H}_{2} \mathrm{SO}_{4}$ solutions in the temperature range $298-203 \mathrm{~K}$ from the analysis of specular reflectance IR spectra.
Nevertheless, there remain significant differences between the individual laboratory data sets of optical constants, the reason for which, as Biermann et al. (2000) noted, is still unclear. A comparison of the different data sets is presented in Fig. 1, that shows an example of the $\mathrm{H}_{2} \mathrm{SO}_{4} / \mathrm{H}_{2} \mathrm{O}$ as well as the $\mathrm{HNO}_{3} / \mathrm{H}_{2} \mathrm{O}$ systems. Note that especially in the wavenumber region of $1500-1000 \mathrm{~cm}^{-1}$, which covers a major part of the sulphate and nitrate absorption region, the deviations between the refractive indices are up to $30 \%$. Clearly, the results of the retrieval algorithms in remote sensing applications will strongly depend on which of the individual data sets of complex refractive indices is used. So far, 


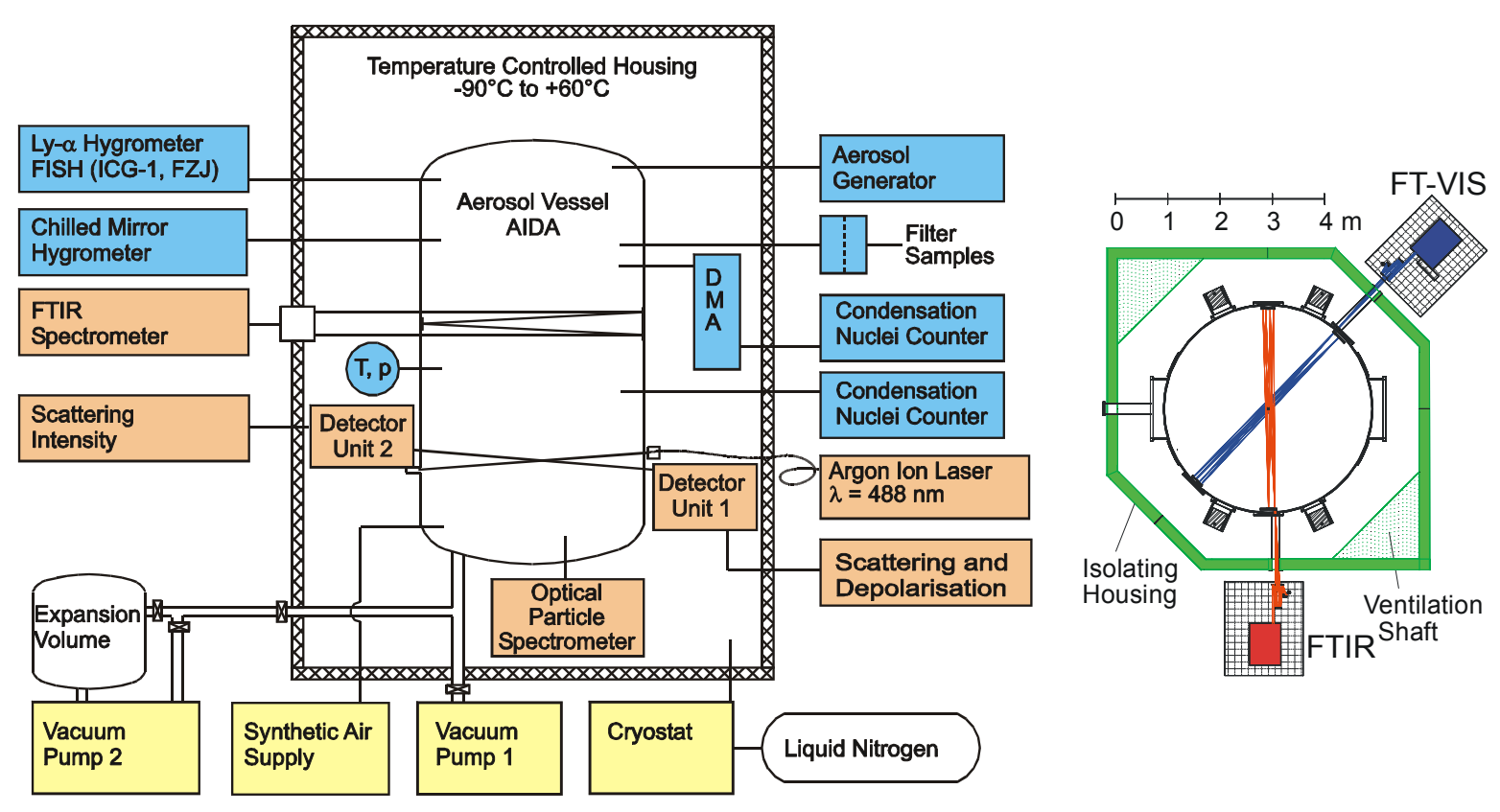

Fig. 2. Left: Schematic cross section of the AIDA facility. Part of the instrumentation, e.g. the in-situ laser scattering/depolarisation unit and the optical particle spectrometer were not used in this study. Right: Cross sectional view of AIDA level 2 showing the set-up for the in situ FTIR extinction measurements. A White cell arrangement is availabe for in-situ measurements of extinction spectra in the UV/VIS region.

no laboratory study has addressed the question which of the data sets is the most reliable and should be used as input for the retrieval algorithms.

In the present study, a comprehensive test of the different data sets of optical constants is presented to assess the accuracy by which experimental low-temperature FTIR spectra of supercooled liquid sulphuric and nitric acid droplets can be quantitatively analysed in terms of aerosol composition and mass concentration based on the published complex refractive indices. The experiments were conducted at the AIDA aerosol chamber facility of Forschungszentrum Karlsruhe which can be cooled to simulate the conditions prevailing in the upper troposphere and lower stratosphere. FTIR spectra of supercooled $\mathrm{H}_{2} \mathrm{SO}_{4} / \mathrm{H}_{2} \mathrm{O}$ and $\mathrm{HNO}_{3} / \mathrm{H}_{2} \mathrm{O}$ droplets were recorded for different aerosol compositions and were analysed by applying a fitting algorithm based on Mie theory. The published data sets of low-temperature optical constants were used in this fit algorithm to retrieve aerosol composition, volume, and mass concentration of the aerosol particles. The results of the retrieval procedure are then compared to simultaneously measured aerosol parameters using complementary methods (filter analysis, humidity measurements, and thermodynamic equilibrium model).

\section{Experimental}

Figure 2 (left side) shows a schematic cross section of the AIDA aerosol chamber facility together with the major scientific instrumentation used in this study. The cylindrical aluminium vessel, volume $84.3 \mathrm{~m}^{3}$, is mounted inside a huge isolating housing whose temperature can be controlled in the range +60 to $-90^{\circ} \mathrm{C}$. The temperature inhomogeneity in the aerosol chamber is less than $\pm 0.3 \mathrm{~K}$. Details concerning the cooling system and the temperature measurements are described by Möhler et al. (2003). The following section will be divided into two subsections. Firstly, the AIDA instrumentation for the aerosol generation and characterisation is summarised, focussing on the determination of the aerosol mass concentration and composition. Secondly, the experimental set-up for the in situ FTIR measurements as well as the retrieval procedure to derive aerosol parameters from the infrared extinction spectra will be discussed in detail.

\subsection{Aerosol generation and characterisation}

Submicron sulphuric acid aerosol particles were generated outside the AIDA chamber by dispersing a $20 \mathrm{wt} \%$ sulphuric acid solution in a nozzle at a backing pressure of about 2 bar. After passing a conditioning tube partly filled with $96 \mathrm{wt} \%$ $\mathrm{H}_{2} \mathrm{SO}_{4}$, the aerosol particles were added to the cooled AIDA aerosol vessel (for details see Möhler et al., 2003, Fig. 3). The size distributions, measured with a differential mobility analyser (DMA) connected to a condensation particle counter (CNC3010, TSI), closely fitted log-normal distributions with count median diameters between 0.2 and $0.3 \mu \mathrm{m}$. The number concentration of the aerosol was typically in the range from 10000 to 15000 particles per $\mathrm{cm}^{3}$.

To form supercooled nitric acid solution droplets, two synthetic air flows of $11 / \mathrm{min}$ were passed over thermostated 
reservoirs of nitric acid and water. The temperatures of both reservoirs were adjusted to achieve molar ratios $\mathrm{H}_{2} \mathrm{O}: \mathrm{HNO}_{3}$ of about 3 in the combined carrier gas, which was directly injected into the cold aerosol vessel through a Teflon tube heated to about $293 \mathrm{~K}$. Nitric acid droplets then formed by nucleation and condensation of the supersaturated $\mathrm{HNO}_{3}$ and water vapours.

The final composition of the sulphuric and nitric acid droplets inside the AIDA chamber is a function of the gas temperature and the relative humidity. By pre-coating the aluminium walls of the aerosol chamber with a thin ice film to establish ice-saturated conditions (Möhler et al., 2003), dilute droplets are obtained. Under these conditions the composition of supercooled sulphuric and nitric acid droplets at $200 \mathrm{~K}$ amounts to $37 \mathrm{wt} \% \mathrm{H}_{2} \mathrm{SO}_{4}$ and $41 \mathrm{wt} \% \mathrm{HNO}_{3}$, calculated with the AIM thermodynamic model (Carslaw et al., 1995; Clegg et al., 1998), available via the world wide web under http://mae.ucdavis.edu/wexler/aim. To generate more concentrated solution droplets which span a larger part of the concentration range of the published data sets of optical constants, several experiments were performed at lower relative humidities. In summary, three experiments were conducted in the $\mathrm{H}_{2} \mathrm{SO}_{4} / \mathrm{H}_{2} \mathrm{O}$ system, covering compositions of about 40,55 , and $80 \mathrm{wt} \% \mathrm{H}_{2} \mathrm{SO}_{4}$, as well as two experiments in the $\mathrm{HNO}_{3} / \mathrm{H}_{2} \mathrm{O}$ system with an aerosol composition of about 45 and $55 \mathrm{wt} \% \mathrm{HNO}_{3}$. The temperature range of the measurements extended from $235 \mathrm{~K}$ down to $192 \mathrm{~K}$ (Table 1).

Total aerosol sulphate and nitrate mass concentrations were determined by ion chromatographic analysis of nylon filter samples (type Nylasorb®, GelmanSciences). Unexposed filters were analysed in the same manner as loaded filters for background correction. The filter holders were located outside the cold housing. Sulphuric acid was collected on a Nylon filter through a stainless steel tube of $1.5 \mathrm{~m}$ length and $4 \mathrm{~mm}$ inner diameter. Less than $1 \%$ sulphuric acid aerosol is lost in the cold sampling line for this configuration. Sulphuric acid is partially lost by evaporation when sampled on Teflon filters at room temperature under very dry conditions. However, this breakthrough effect does not occur on Nylon membrane filters, as was shown by using Nylon back-up filters. Since $\mathrm{HNO}_{3}$ adsorbs on stainless steel, a Teflon tube maintained at $293 \mathrm{~K}$ was used to sample this compound. Neuman et al. (1999) reported that significant adsorption of nitric acid on Teflon occurs only above $60 \%$ relative humidity at this temperature. Under our conditions (relative humidity $<1 \%$ at $293 \mathrm{~K}$ ) nitric acid is quantitatively passed to the Nylon filter. We could show by detecting $\mathrm{HNO}_{3}$ with a chemical ionisation mass spectrometer that significant adsorptive losses occurred only when the Teflon tube temperature drops below $240 \mathrm{~K}$. The Nylon filters collect nitric acid vapour from particles evaporating in the sampling tube, residual particles, and interstitial $\mathrm{HNO}_{3}$ vapour in equilibrium with the particles from the aerosol vessel. However, due to the low temperatures, interstitial $\mathrm{HNO}_{3}$ vapour represents a very small fraction $(\sim 1 \%)$ of the predominantly particle- bound $\mathrm{HNO}_{3}$ content of the chamber. To correct for breakthrough effects, $\mathrm{HNO}_{3}$ was collected on two Nylon filters in series. Goldan et al. (1983) reported no measurable breakthrough of $\mathrm{HNO}_{3}$ for filter loadings up to $2.2 \mu \mathrm{g} / \mathrm{cm}^{2}$. However, in our experiments up to $10 \%$ nitric acid was recovered on the back-up filters at loadings up to $3 \mu \mathrm{g} / \mathrm{cm}^{2}$. Thus, the total loss was of the order of $1 \%$ in our experiments. Including the uncertainty of the ion chromatographic analysis we estimate the relative uncertainty in the sulphuric and nitric acid mass concentration to be $10 \%$ or better, as confirmed by a good agreement between sulphate volume concentrations derived from filter analyses and from size distribution measurements in recent AIDA experiments (Fig. 4 in Möhler et al., 2003).

To calculate the composition of aerosol particles in the chamber with the AIM model, the total water mixing ratio must be known in addition to the sulphate or nitrate mass concentrations. The total water mixing ratio was measured with the fast in-situ Lyman- $\alpha$ hygrometer (FISH) of Forschungszentrum Jülich (Zöger et al., 1999), run however as an ex-situ instrument during these experiments. The overall accuracy of the FISH instrument is reported to be about $6 \%$ with a detection limit of about $0.2 \mathrm{ppm}$. As a heated stainless steel sampling tube $\left(>20^{\circ} \mathrm{C}\right.$, inner diameter $\left.10 \mathrm{~mm}\right)$ was used, the water mixing ratio recorded by the FISH instrument corresponds to the sum of interstitial and evaporated particle water. The aerosol water content and thus the aerosol composition is obtained by partitioning total water between the gas and the liquid phases according to the AIM model. For the experiment with the most concentrated sulphuric acid droplets (about $80 \mathrm{wt} \% \mathrm{H}_{2} \mathrm{SO}_{4}$ ), the relative humidity was outside the validity range of the Clegg and Brimblecombe model. Therefore a recent parameterisation of the $\mathrm{H}_{2} \mathrm{SO}_{4} / \mathrm{H}_{2} \mathrm{O}$ aerosol composition by Tabazadeh et al. (1997) was employed. Their expression for the water vapour pressure in equilibrium with aqueous $\mathrm{H}_{2} \mathrm{SO}_{4}$ is consistent with the Clegg and Brimblecombe model in the temperature range of 185 to $260 \mathrm{~K}$ but applicable up to a composition of $80 \mathrm{wt} \%$ $\mathrm{H}_{2} \mathrm{SO}_{4}$.

\subsection{FTIR measurements and retrieval of aerosol parameters}

Extinction spectra of supercooled solution droplet aerosols were measured in-situ with a White-type multiple reflection cell yielding a horizontal optical path of $254.3 \mathrm{~m}, 3.5 \mathrm{~m}$ above the bottom of the $7 \mathrm{~m}$ high AIDA vessel, as shown schematically in Fig. 2. Spectra were recorded with a Bruker IFS 66v FTIR spectrometer in the wavenumber range from $\tilde{v}=800$ to $6000 \mathrm{~cm}^{-1}$ at a resolution of $4 \mathrm{~cm}^{-1}$, using barium fluoride as window material. 500 scans were co-added to yield sample spectra $I(\tilde{v})$. Background spectra $I_{0}(\tilde{v})$ were recorded before each experiment with no aerosol particles present. To prevent icing and to minimise the deposition of acid droplets, the mirrors of the White system were heated to well above the AIDA wall temperature. 
Table 1. Comparison of aerosol parameters retrieved from the analysis of the FTIR extinction spectra using different optical constants (lower part) with those derived from filter sampling and humidity measurements (top part)

\begin{tabular}{lccccc}
\hline List of Experiments & Case 1 & Case 2 & Case 3 & Case 4 & Case 5 \\
\hline aerosol type & $\mathrm{H}_{2} \mathrm{SO}_{4} / \mathrm{H}_{2} \mathrm{O}$ & $\mathrm{H}_{2} \mathrm{SO}_{4} / \mathrm{H}_{2} \mathrm{O}$ & $\mathrm{H}_{2} \mathrm{SO}_{4} / \mathrm{H}_{2} \mathrm{O}$ & $\mathrm{HNO}_{3} / \mathrm{H}_{2} \mathrm{O}$ & $\mathrm{HNO}_{3} / \mathrm{H}_{2} \mathrm{O}$ \\
AIDA temperature / K & 234.8 & 232.8 & 195.4 & 195.0 & 191.6 \\
\hline $\mathrm{wt} \% \mathrm{H}_{2} \mathrm{SO}_{4}, \mathrm{HNO}_{3}$ & $79.2 \pm 0.5$ & $56.0 \pm 0.5$ & $37.7 \pm 3.0$ & $46.2 \pm 1.8$ & $52.4 \pm 2.0$ \\
$\begin{array}{l}\mathrm{m}\left(\mathrm{sulphhate}^{3}, \text { nitrate }\right) / \\
\mu \mathrm{g} / \mathrm{m}^{3}\end{array}$ & $710 \pm 70$ & $470 \pm 50$ & $320 \pm 30$ & $200 \pm 20$ & $380 \pm 40$ \\
\hline
\end{tabular}

\section{FTIR fit results}

\begin{tabular}{|c|c|c|c|c|c|}
\hline \multicolumn{6}{|l|}{$\begin{array}{l}\text { Niedziela et al., 1999/ } \\
\text { Norman et al., } 1999\end{array}$} \\
\hline $\mathrm{wt} \% \mathrm{H}_{2} \mathrm{SO}_{4}, \mathrm{HNO}_{3}$ & $80 \pm 2$ & $55 \pm 2$ & $39 \pm 2$ & $47 \pm 2$ & $56 \pm 2$ \\
\hline $\begin{array}{l}\mathrm{m} \text { (sulphate, nitrate) / } \\
\mu \mathrm{g} / \mathrm{m}^{3}\end{array}$ & $800 \pm 40$ & $500 \pm 25$ & $375 \pm 25$ & $200 \pm 10$ & $480 \pm 20$ \\
\hline \multicolumn{6}{|l|}{ Biermann et al., 2000} \\
\hline $\mathrm{wt} \% \mathrm{H}_{2} \mathrm{SO}_{4}, \mathrm{HNO}_{3}$ & $80 \pm 2$ & $61 \pm 2$ & $37 \pm 2$ & $41 \pm 2$ & - \\
\hline $\begin{array}{l}\mathrm{m} \text { (sulphate, nitrate }) / \\
\mu \mathrm{g} / \mathrm{m}^{3}\end{array}$ & $800 \pm 40$ & $620 \pm 30$ & $330 \pm 20$ & $165 \pm 10$ & - \\
\hline
\end{tabular}

Tisdale et al., 1998

$\begin{array}{lcc}\text { wt } \% \mathrm{H}_{2} \mathrm{SO}_{4} & 80 \pm 2 & 55 \pm 2 \\ \mathrm{~m}(\text { sulphate }) / \mu \mathrm{g} / \mathrm{m}^{3} & 770 \pm 40 & 505 \pm 25\end{array}$

Myhre et al., 2003

$\begin{array}{lrrr}\text { wt } \% \mathrm{H}_{2} \mathrm{SO}_{4} & 81 \text { (fixed)* } & 53 \pm 2 & 38 \text { (fixed)* } \\ \mathrm{m}(\text { sulphate }) / \mu \mathrm{g} / \mathrm{m}^{3} & 875 \pm 45 & 510 \pm 25 & 335 \pm 25\end{array}$

* no retrieval of aerosol composition

The quantitative analysis of the FTIR spectra is based on the Lambert Beer Eq. (1). The optical density of an aerosol is proportional to the aerosol number density $N$, the sizeaveraged extinction cross section $\left\langle\mathrm{C}_{\mathrm{ext}}\right\rangle$, and the optical path length $L$ :

optical density $(\tilde{v})=-\log \frac{I(\tilde{v})}{I_{0}(\tilde{v})}=\frac{N(\tilde{v})\left\langle\mathrm{C}_{\text {ext }}(\tilde{v})\right\rangle L}{\ln 10}$

Spectra calculated from Mie theory were fitted to the measured FTIR extinction spectra of the spherical supercooled solution droplets. All data sets of optical constants quoted in the introduction were used as input values for these calculations. The computation was based on the algorithm of Bohren and Huffman (1983), extended to average the computed extinction cross sections $\mathrm{C}_{\mathrm{ext}}$ over log-normally distributed particle sizes,

$\phi\left(D_{p}\right)=\frac{1}{\sqrt{2 \pi} D_{P} \ln \sigma_{g}} \exp \left\{-\frac{\left(\ln D_{P}-\ln C M D\right)^{2}}{2\left(\ln \sigma_{g}\right)^{2}}\right\}$, where $\phi\left(D_{P}\right) d D_{p}$ denotes the fraction of particles per unit volume having diameters between $D_{P}$ and $D_{P}+d D_{P}$ (Hinds, 1999). Using Powell's multidimensional optimisation method (Press et al., 1988, 1992), the aerosol number density $N$ as well as the count median diameter $C M D$ and the mode width $\sigma_{g}$ of the log-normal size distribution were retrieved by minimising the summed squared residuals between experimental and calculated spectra. As discussed in numerous publications (Bertram and Sloan, 1998; Disselkamp et al., 1996; Echle et al., 1998; Eldering et al., 2001), the fit becomes insensitive to the parameters $C M D$ and $\sigma_{g}$ when the particle radii are small compared to the wavelength of the incident radiation, i.e. approach the Rayleigh limit of Mie theory. In the limit of very small particles, the absorption cross section is proportional to the volume of the particles, independent of their sizes. Therefore, since the radii of the supercooled $\mathrm{H}_{2} \mathrm{SO}_{4} / \mathrm{H}_{2} \mathrm{O}$ and $\mathrm{HNO}_{3} / \mathrm{H}_{2} \mathrm{O}$ droplets studied in this work were in the sub- $\mu \mathrm{m}$ size range, 

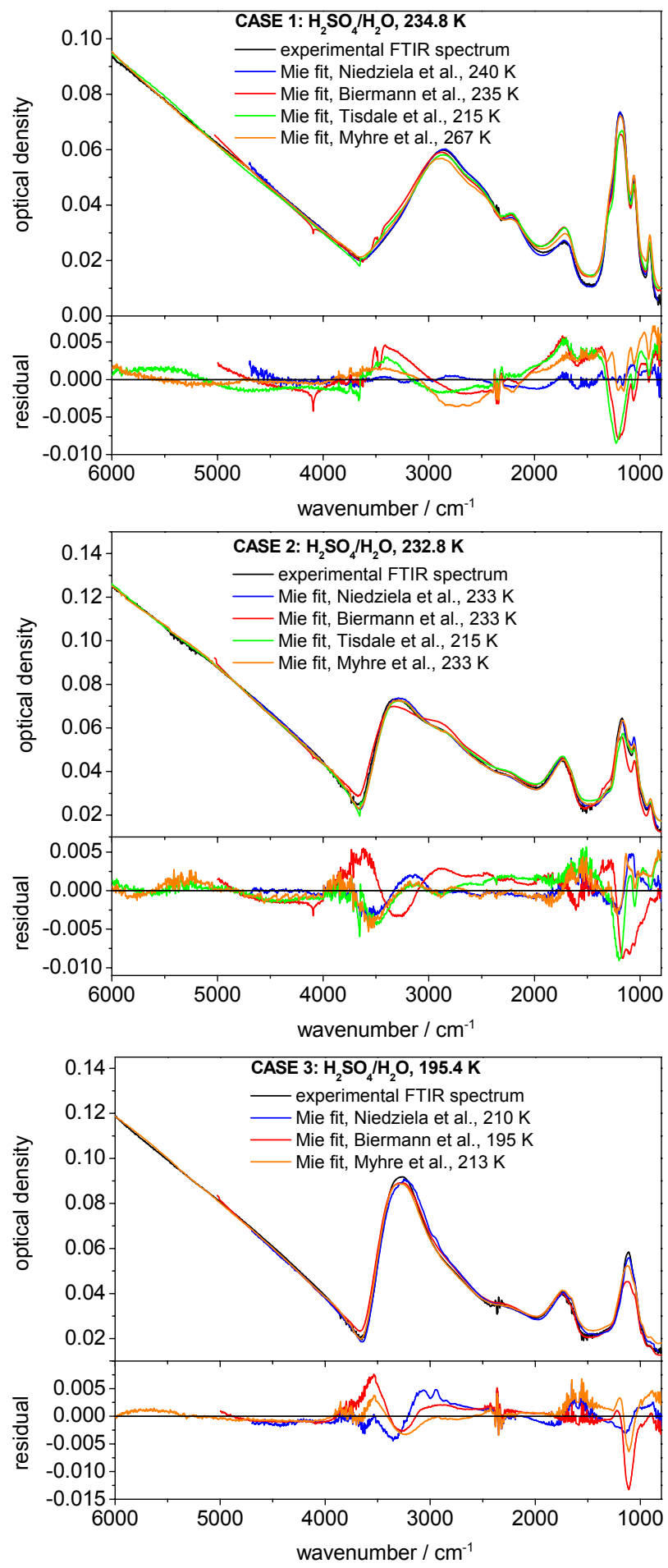

Fig. 3. FTIR extinction spectra of supercooled sulphuric acid droplets obtained in this work and best fit results based on Mie calculations with different published data sets of optical constants. Top: case 1 (79.2 $\mathrm{wt} \% \mathrm{H}_{2} \mathrm{SO}_{4}$ ), middle: case 2 (56.0 $\mathrm{wt} \% \mathrm{H}_{2} \mathrm{SO}_{4}$ ), bottom: case $3\left(37.6 \mathrm{wt} \% \mathrm{H}_{2} \mathrm{SO}_{4}\right)$. The retrieved aerosol compositions and mass concentrations are summarised in Table 1.
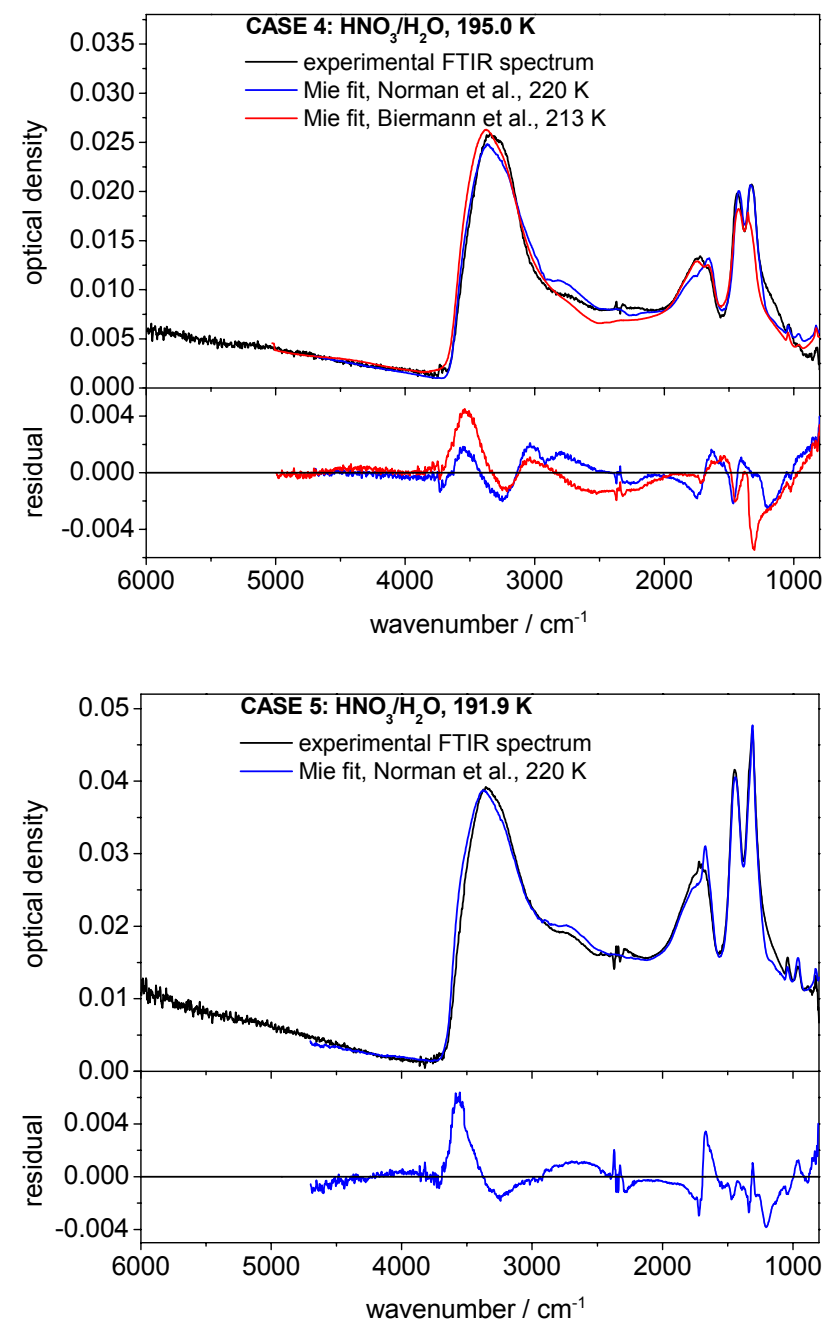

Fig. 4. Experimental FTIR extinction spectra of supercooled nitric acid droplets and best fit results from Mie calculations using different data sets of published optical constants. Top: case 4 (46.2 wt\% $\left.\mathrm{HNO}_{3}\right)$; bottom: case $5\left(52.4 \mathrm{wt} \% \mathrm{HNO}_{3}\right)$. The retrieved aerosol compositions and mass concentrations are summarised in Table 1.

well below the wavelength range of the FTIR spectra, we can obtain different sets of $N, \sigma_{g}$, and $C M D$ which lead to almost the same summed squared minima. These sets of size distribution parameters, however, correspond to the identical aerosol volume density $V$. Consequently, only volume densities can be retrieved unambiguously from our measured FTIR spectra. To derive the composition of the droplets, repeated Mie-fits were performed for each of the available input data sets of optical constants, using $N, \sigma_{g}$ and $C M D$ as fitting parameters. Based on the interpolation schemes provided in the papers cited above, sets of optical constants were calculated in steps of $2 \mathrm{wt} \% \mathrm{H}_{2} \mathrm{SO}_{4}$ or $\mathrm{HNO}_{3}$, respectively. The best fit and thus the most likely aerosol composition minimised the summed squared residuals. From the fit parameters $N, \sigma_{g}$ and $C M D$, the total aerosol volume density $V$ was 
calculated using the analytical expression

$V\left(N, \sigma_{g}, C M D\right)=\frac{1}{6} \pi \cdot N \cdot C M D^{3} \exp \left(\frac{9}{2}\left(\ln \sigma_{g}\right)^{2}\right)$

(Echle et al., 1998; Lee et al., 1984). The total aerosol mass concentration can then be calculated by multiplying the aerosol volume density $V$ with the density of the supercooled $\mathrm{H}_{2} \mathrm{SO}_{4} / \mathrm{H}_{2} \mathrm{O}$ and $\mathrm{HNO}_{3} / \mathrm{H}_{2} \mathrm{O}$ droplets. To estimate the lowtemperature densities of aqueous $\mathrm{H}_{2} \mathrm{SO}_{4}$ and $\mathrm{HNO}_{3}$, we used the extrapolation formula given by Carslaw et al. (1995), eq. A10. Recent measurements of the low-temperature densities of sulphuric acid solutions agree with the extrapolation results to within $\pm 2 \%$ (Beyer et al., 1996; Myhre et al., 1998; Myhre et al., 2003). Using the retrieved particle composition, the particle water content was subtracted from the total particle mass concentration yielding finally the sulphate respectively nitrate mass concentration which can be directly compared to the values determined with the filter sampling technique.

\section{Results and discussion}

\subsection{Overview of results}

The results of the retrieval procedure are presented in the following order: Cases 1, 2, and 3 refer to the experiments with supercooled $\mathrm{H}_{2} \mathrm{SO}_{4} / \mathrm{H}_{2} \mathrm{O}$ solution droplets, cases 4 and 5 to the $\mathrm{HNO}_{3} / \mathrm{H}_{2} \mathrm{O}$ system. The corresponding AIDA temperatures and the aerosol composition and mass concentrations based on filter analyses and measurements of total water are listed in the upper panel of Table 1. The errors of the tabulated aerosol compositions were determined by taking into account the uncertainties of the measured aerosol mass concentration $( \pm 10 \%)$, the AIDA gas temperature $( \pm 0.3 \mathrm{~K})$, and the total water measurements with the FISH instrument $( \pm 6 \%)$ when applying the AIM model to calculate the droplet composition. Figures 3 and 4 show FTIR extinction spectra of the aerosol particles measured in this work, together with the best fit results from the Mie calculations based on different data sets of optical constants. Note that the Mie-fitted extinction spectra cover different wavelength ranges, depending on the validity ranges of the published optical constants. The temperature for which the optical constants were extracted from the various interpolation schemes are noted in the figure panels.

When discussing differences between experimental and Mie-calculated infrared spectra it should be kept in mind that in some cases either the complex refractive indices were only measured at a single temperature or the tabulated values did not extend to temperatures below $200 \mathrm{~K}$. Hence there remain occasionally differences between the actual AIDA temperatures and the temperatures for which the adopted optical constants were determined. Due to its limited aerosol composition range, the data set of Tisdale et al. (1998) could only be adopted in cases 1 and 2 of the sulphuric acid system. For the same reason, the FTIR extinction spectrum of the concentrated nitric acid droplets (case 5) could not be fitted with the Biermann et al. (2000) data set. Furthermore, the aerosol compositions in case 1 and case 3 are close to the high and low concentration limits of the interpolation scheme provided by Myhre et al. (2003). The authors have pointed out that there is significant disagreement (up to 10\%) between the experimentally obtained complex refractive indices and those calculated by means of the interpolation scheme for low temperatures and low concentrations. Therefore, in case 3 we used the original real and imaginary parts of the refractive index (the $n$ and $k$ data set) for $38 \mathrm{wt} \% \mathrm{H}_{2} \mathrm{SO}_{4}(213 \mathrm{~K})$ to fit the measured FTIR spectrum instead of varying the input data set in steps of $2 \mathrm{wt} \%$ sulphuric acid. Also, in case 1 the experimental spectrum was fitted with the original data set for $81 \mathrm{wt} \% \mathrm{H}_{2} \mathrm{SO}_{4}(267 \mathrm{~K})$. The results of the retrieval procedure, i.e. the aerosol composition and mass concentration derived from the analysis of the FTIR spectra, are presented in the lower panel of Table 1. The uncertainties of the sulphate and nitrate mass concentrations reflect $\pm 2 \mathrm{wt} \%$ uncertainty in composition, which was the step size used in the retrieval procedure.

\subsection{The $\mathrm{H}_{2} \mathrm{SO}_{4} / \mathrm{H}_{2} \mathrm{O}$ system}

Very good agreement between experimental FTIR and Miefitted spectra is obtained when applying the Niedziela et al. (1999) data set of optical constants to the $\mathrm{H}_{2} \mathrm{SO}_{4} / \mathrm{H}_{2} \mathrm{O}$ system (Fig. 3). In all cases the recorded infrared spectra are nicely reproduced by the Mie fit, except for a very small spectral mismatch in the broad $\mathrm{OH}$ extinction feature centred at around $3300 \mathrm{~cm}^{-1}$ in case $3\left(38 \mathrm{wt} \% \mathrm{H}_{2} \mathrm{SO}_{4}\right)$. This is most likely due to the difference between the actual AIDA temperature $(195 \mathrm{~K})$ and the lowest temperature $(210 \mathrm{~K})$ for which the optical constants for aerosol of this composition are available. Table 1 shows that the retrieved aerosol compositions agree to within $\pm 2 \mathrm{wt} \%$ with the measured ones and also the retrieved sulphate mass concentrations agree within their error limits with the filter analytical results. These results contrast with the quality of the Mie fits based on the optical constants of Biermann et al. (2000) which is much poorer. As shown in Fig. 3, large residuals remain at wavenumbers below $2000 \mathrm{~cm}^{-1}$, especially in the regime of the absorption bands associated with $\mathrm{HSO}_{4}^{-}$and $\mathrm{SO}_{4}^{2-}$ around $1100 \mathrm{~cm}^{-1}$, where the optical density is significantly underestimated. Note that the poor quality of the Biermann et al. (2000) data set in this frequency region does not necessarily lead to large errors in the retrieved aerosol composition and mass concentration: in cases 1 and 3 of this study the retrieved aerosol parameters are as good as those retrieved with the Niedziela et al. (1999) data set of optical constants. In both cases, the overall good agreement between measured and calculated spectra in the 5000 to $2000 \mathrm{~cm}^{-1}$ regime compensates for the spectral mismatch in the low frequency region. Only in case 2 are the retrieved $\mathrm{H}_{2} \mathrm{SO}_{4}$ 
concentration and sulphate mass concentration considerably overestimated.

But it is important to note that, in cases 1 and 3, the derived aerosol parameters are only in good agreement with the measured ones when the whole wavenumber range from 5000 to $800 \mathrm{~cm}^{-1}$ is included in the fit. In remote sensing applications, however, large parts of this regime are obscured by strong gas absorption features and thus cannot be used to retrieve particle properties. Furthermore, the accessible wavenumber range for measurements with infrared emission sounding instruments is limited due to the strongly decreasing thermal emission of the atmosphere at shorter wavelengths (e.g. wavenumber regime $2410-685 \mathrm{~cm}^{-1}$ with MIPAS-ENVISAT, http://envisat.esa. int/instruments/mipas/descr/charact/). For example, Eldering et al. (2001) in an analysis of ATMOS measurements, used two wavenumber intervals from $820-990 \mathrm{~cm}^{-1}$ and $1070-1240 \mathrm{~cm}^{-1}$ to study sulphuric acid aerosols. As a check, we have repeated the retrieval procedure for case 1 , now limiting the wavenumber regime of the Mie fit procedure to these spectral intervals. This leads to a sulphate mass concentration of about $910 \mu \mathrm{g} / \mathrm{m}^{3}$ when using the Biermann data set for $80 \mathrm{wt} \% \mathrm{H}_{2} \mathrm{SO}_{4} / \mathrm{H}_{2} \mathrm{O}$ solutions, compared to $710 \mu \mathrm{g} / \mathrm{m}^{3}$ based on filter analyses. Similar overestimations of the sulphate mass concentration are obtained in cases 2 and 3. This contrasts with fit results based on refractive indices of Niedziela et al. (1999) which are nearly insensitive to the wavenumber interval chosen.

With the Tisdale et al. (1998) data set the agreement between the Mie fits and the measured extinction spectra falls between the two former data sets. There is also a tendency to underestimate the measured optical density in the $\mathrm{HSO}_{4}^{-} / \mathrm{SO}_{4}^{2-}$ extinction regime. However, as already noted by Niedziela et al. (1999) when comparing their data sets of optical constants with those of Tisdale et al. (1998), at least part of the differences might be due to the fact that the Tisdale et al. (1998) data sets were determined at temperatures around $215 \mathrm{~K}$, thereby introducing an error as a result of the temperature dependent ion equilibria in the $\mathrm{H}_{2} \mathrm{SO}_{4} / \mathrm{H}_{2} \mathrm{O}$ system. Nonetheless, the retrieved aerosol parameters based on the Tisdale et al. (1998) optical constants agree very well with the measured ones when including the whole wavenumber regime in the retrieval procedure.

Finally, we want to address the Myhre et al. (2003) data set of optical constants. Unfortunately, as already mentioned in Sect. 3.1, only in case 2 the optical constants could be interpolated to the actual AIDA temperature. The quality of this fit result is impressive: the Mie calculation is in excellent agreement with the FTIR spectrum measured in the AIDA chamber, and so are the retrieved aerosol parameters. In case 3 the difference between the AIDA temperature and the temperature for which the employed optical constants were determined is $18 \mathrm{~K}$, and in case 1 even $32 \mathrm{~K}$ (see Fig. 3), which most likely explains the poorer quality of the Mie fits in these cases.
Myhre et al. (2003) have pointed out that special care has to be taken when performing the Kramers-Kronig transformation which is an essential step in deriving the real and imaginary parts of the complex refractive index in all of the studies mentioned in the introduction. In particular, they found that the neglect of the far infrared spectral region in the Kramers-Kronig integral might lead to large errors in the absorption index of $5-75 \%$. Therefore, the authors have argued that the observable discrepancies between their data set of optical constants with the Niedziela et al. (1999) and Biermann et al. (2000) sets are due to the fact, that (a) Niedziela et al. (1999) only investigated the $4700-825 \mathrm{~cm}^{-1}$ region (but including the room-temperature optical constants of Palmer and Williams (1975) in the $825-400 \mathrm{~cm}^{-1}$ region), and that (b) Biermann et al. (2000) have assumed a monotonous decrease in the far infrared absorption in contrast with the measurements of Myhre et al. (2003) which even showed an increase of reflectance in this spectral region.

Yet we believe that potential inaccuracies in the application of the Kramers-Kronig transformation are only one criterion to account for the apparent differences between the various data sets of optical constants. Firstly we want to note that the differences between the Niedziela et al. (1999) and Myhre et al. (2003) data sets are much smaller compared to the Biermann et al. (2000) optical constants. Myhre et al. (2003) reported that in individual cases their absorption spectrum $k(\tilde{v})$ differs from the Niedziela et al. (1999) study by as much as $10-20 \%$. In other cases, however, the agreement is excellent. An example is presented in the top part of Fig. 5, which compares the Niedziela et al. (1999) and Myhre et al. (2003) $n$ and $k$ data sets for $81 \mathrm{wt}^{2} \mathrm{H}_{2} \mathrm{SO}_{4}$ at $267 \mathrm{~K}$. Another example is presented in the lower part of Fig. 5 for $58 \mathrm{wt} \% \mathrm{H}_{2} \mathrm{SO}_{4}$ at $233 \mathrm{~K}$. Interestingly, in the latter case the agreement between the data sets is fairly good over the whole frequency regime, but the spectral shape of the sulphate absorption band at about $1100 \mathrm{~cm}^{-1}$ is quite different. We believe that this might be explained by the iterative approach employed by Niedziela et al. (1999) to extract the optical constants from their aerosol extinction spectra, previously applied to a large variety of different aerosol species like water ice, NAD and NAT (Clapp et al., 1995; Niedziela et al., 1998; Richwine et al., 1995). They used a "non-scattering" spectrum of very small aerosol particles for an initial guess of $k(\tilde{v})$, assuming that the optical density was directly proportional to the imaginary index $k$. The corresponding real part of the refractive index is then obtained from a subtractive Kramers-Kronig calculation. The imaginary index scaling factor is afterwards determined by fitting a large particle spectrum exhibiting a strong scattering component. However, according to Rayleigh theory, the absorption cross section $\mathrm{C}_{\mathrm{abs}}$ for transmission measurements in air is written as

$\mathrm{C}_{\mathrm{abs}}=\frac{8 \pi^{2} r^{3}}{\lambda} \operatorname{Im}\left\{\frac{(n-i k)^{2}-1}{(n-i k)^{2}+2}\right\}$, 

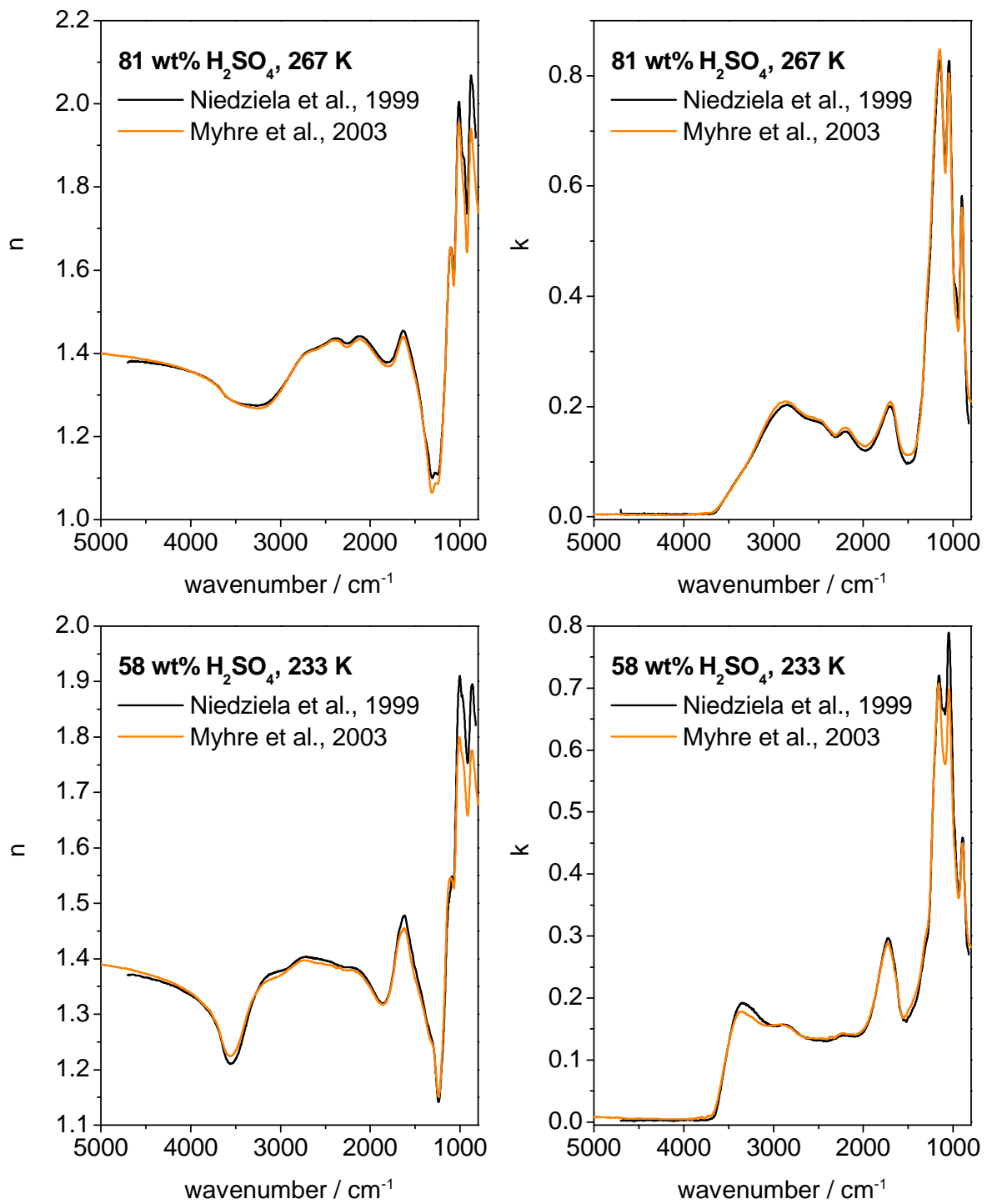

Fig. 5. Comparison of the Niedziela et al. (1999) and Myhre et al. (2003) data sets of optical constants for $\mathrm{H}_{2} \mathrm{SO}_{4} / \mathrm{H}_{2} \mathrm{O}$. Upper panels: $81 \mathrm{wt} \% \mathrm{H}_{2} \mathrm{SO}_{4}, 267 \mathrm{~K}$; lower panels: $58 \mathrm{wt} \% \mathrm{H}_{2} \mathrm{SO}_{4}, 233 \mathrm{~K}$.

where $r$ denotes the particle radius, and $(n, k)$ the optical constants of the particle (Bohren and Huffman, 1983). So, the optical density, even when recording a truly non-scattering aerosol spectrum, is not directly proportional to $k$ as in bulk absorption spectra. Therefore, the authors had to adjust their initial set of $n$ and $k$ data by an iterative procedure, noting that a Mie calculation using the original $n$ and $k$ spectrum resulted in differences between the experimental small-particle spectrum and the result of the fit (Clapp et al., 1995).

We believe that a more straightforward and mathematically proven method to derive optical constants from small particle transmission spectra was presented by Ossenkopf et al. (1992). They have noted that the Kramers-Kronig relation also applies to the composite function $f(\lambda)=\{[n(\lambda)-$ $\left.i k(\lambda)]^{2}-1\right\} /\left\{[n(\lambda)-i k(\lambda)]^{2}+2\right\}$. Its imaginary part can di- rectly be obtained from the transmission spectra using Eq. (4) with the assumption that the scattering is small and the measured extinction is the same as the absorption. After the Kramers-Kronig integration the optical constants can be easily calculated from the real and imaginary parts of $f(\lambda)$. By using this method, the iterative adjustment of the original, approximated $n$ and $k$ spectrum in the Niedziela et al. (1999) approach could be avoided. The top part of Fig. 6 shows a calculated small-particle extinction spectrum of $58 \mathrm{wt} \%$ $\mathrm{H}_{2} \mathrm{SO}_{4}$ at $233 \mathrm{~K}$, based on the optical constants of Myhre et al. (2003). The lower panel presents the $k$ spectrum obtained by assuming that the optical density is directly proportional to the imaginary index $k$. The comparison with the actual $k$ spectrum used to calculate the small-particle spectrum makes clear that the error introduced in this initial guess $k$ spectrum 

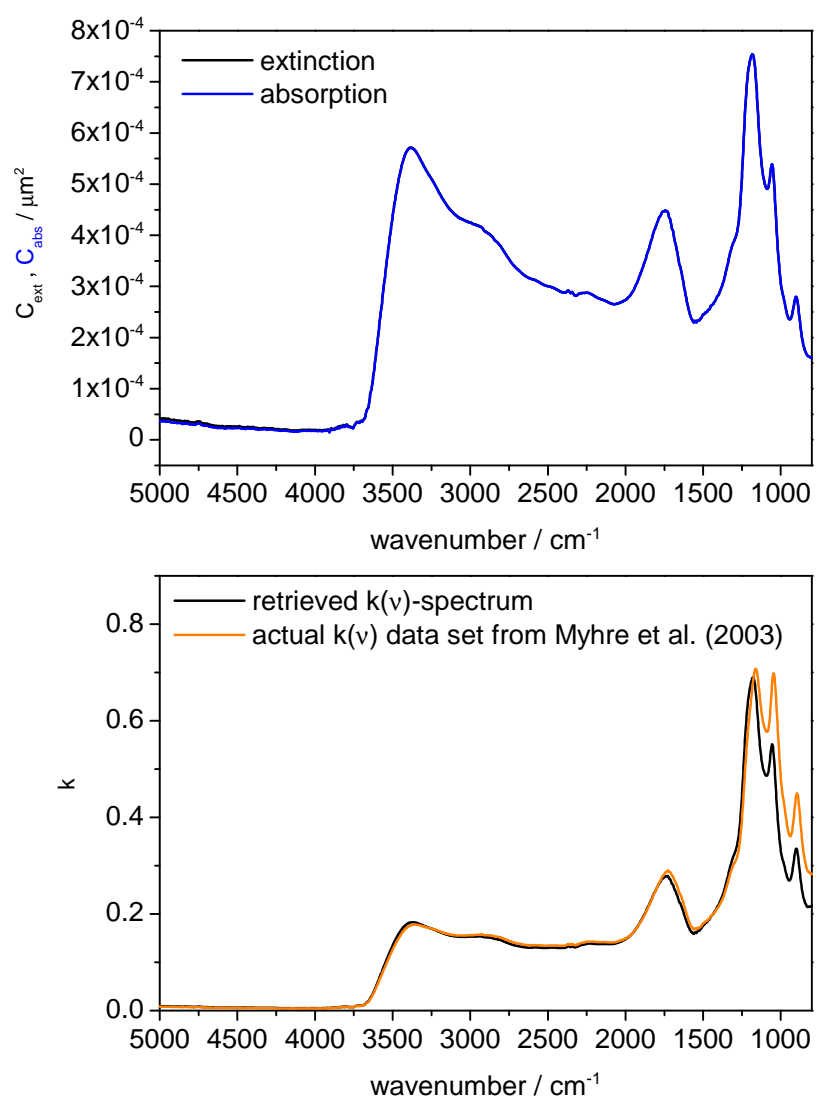

Fig. 6. Initialisation of the $k$ spectrum using the Niedziela et al. (1999) approach. Top panel: calculation of a small particle extinction and absorption spectrum $\left(C M D=0.1 \mu \mathrm{m}, \sigma_{g}=1.4\right)$ using the optical constants of Myhre et al. (2003) for $58 \mathrm{wt} \% \mathrm{H}_{2} \mathrm{SO}_{4}$ at $233 \mathrm{~K}$. Lower panel: retrieved $k$ spectrum based on the assumption that the extinction cross section is directly proportional to $k\left(C_{\text {ext }}(v) \sim k(v)^{*} v\right)$ in comparison with the actual $k$ spectrum for $58 \mathrm{wt} \% \mathrm{H}_{2} \mathrm{SO}_{4}$ used to calculate the small particle spectrum.

is quite large in the sulphate absorption regime. After the Kramers-Kronig transformation the quality of the initial $n$ spectrum will be equally poor in this spectral region. The further empirical adjustment of the original $n$ and $k$ spectra in the Niedziela et al. (1999) approach will certainly improve the quality of the data set. As can be seen in the fit results presented in Fig. 3, our measured FTIR spectra are indeed excellently reproduced by Mie calculations based on the Niedziela et al. (1999) data set of optical constants. Nevertheless, we believe that the occasionally visible small differences in the shapes of the $n$ and $k$ spectra between the Myhre et al. (2003) and Niedziela et al. (1999) data sets in the sulphate absorption regime (see Fig. 5) might be explained by the fact that the initial guess $n$ and $k$ spectra are a poor choice for the actual data sets in the $1500-800 \mathrm{~cm}^{-1}$ spectral region and might lead to a wrong scaling of the $n$ and $k$ values in the further iterative adjustment performed by Niedziela et al. (1999). However, we have to state that within the experimental uncertainty range of our measurements these small spectral differences are not significant, as clearly shown by the fit results in Table 1 .

Concerning the Biermann et al. (2000) data set of optical constants, an incorrect application of the Kramers-Kronig transformation would only influence their $n(\tilde{v})$ spectra but cannot explain the large discrepancies already existent in the $k(\tilde{v})$ spectra (see e.g. Fig. 1), which were directly obtained from their measured thin film transmission spectra. In their recent study dealing with the optical constants of supercooled ternary $\mathrm{H}_{2} \mathrm{SO}_{4} / \mathrm{H}_{2} \mathrm{O} / \mathrm{HNO}_{3}$ solution droplets, Norman et al. (2002) found considerable differences between their measured optical constants and those extracted from the mixing scheme proposed by Biermann et al. (2000), which they traced back to possible problems with the Biermann et al. (2000) binary optical constants. As in the present study, they were unable to accurately fit an experimental FTIR spectrum of $55 \mathrm{wt} \% \mathrm{H}_{2} \mathrm{SO}_{4} / \mathrm{H}_{2} \mathrm{O}$ at $220 \mathrm{~K}$ (conditions similar to case 2 of this study) with the Biermann et al. (2000) data set of optical constants, especially in the $\mathrm{HSO}_{4}^{-} / \mathrm{SO}_{4}^{2-}$ extinction regime near $1100 \mathrm{~cm}^{-1}$. However, they could not give a plausible explanation for the mismatch. Heathfield et al. (1999) pointed out, that measurements on actual aerosol particles might provide data, which are more appropriate for describing real atmospheric aerosol particles than data extracted from thin film measurements, avoiding for example surface interactions between a thin film and its substrate. However, when using a substrate material which is resistant to $\mathrm{H}_{2} \mathrm{SO}_{4} / \mathrm{H}_{2} \mathrm{O}$, there seems to be no ad-hoc reason not to apply thin film optical constants in aerosol particle calculations when the particle sizes are large enough to avoid quantum size effects (Bohren and Huffman, 1983). Another source of a systematic error in the Biermann et al. (2000) data may be due to a simplifying assumption made in their analysis of the thin film data. They determined their optical constants from transmission measurements through sulphuric acid films sandwiched between two $\mathrm{AgBr}$ windows. Stating that "the refractive index of $\mathrm{AgBr}$ is low enough to avoid strong interferences at the transitional layers between the strongly parallel windows and the liquid film", they analysed their transmission spectra by applying

$I(\tilde{v})=I_{0}(\tilde{v}) \exp \left(-\frac{4 \pi \tilde{v} k(\tilde{v})}{x}\right)$,

where $I(\tilde{v})$ denotes the light intensity attenuated by a sulphuric acid film of thickness $x$, and $I_{0}(\tilde{v})$ is the reference spectrum of the empty cell. Thus, multiple reflections occurring between phase boundaries were completely neglected in their analysis, whereas Tisdale et al. (1998) explicitly considered these reflections in the analysis of their thin film spectra. Recently, Rajaram et al. (2001) presented a re-analysis of a transmission spectrum of a water ice sample sandwiched between two glass windows, analysed previously without taking into account multiple reflections within the windows and the ice sample. They found that the $k$ values retrieved 

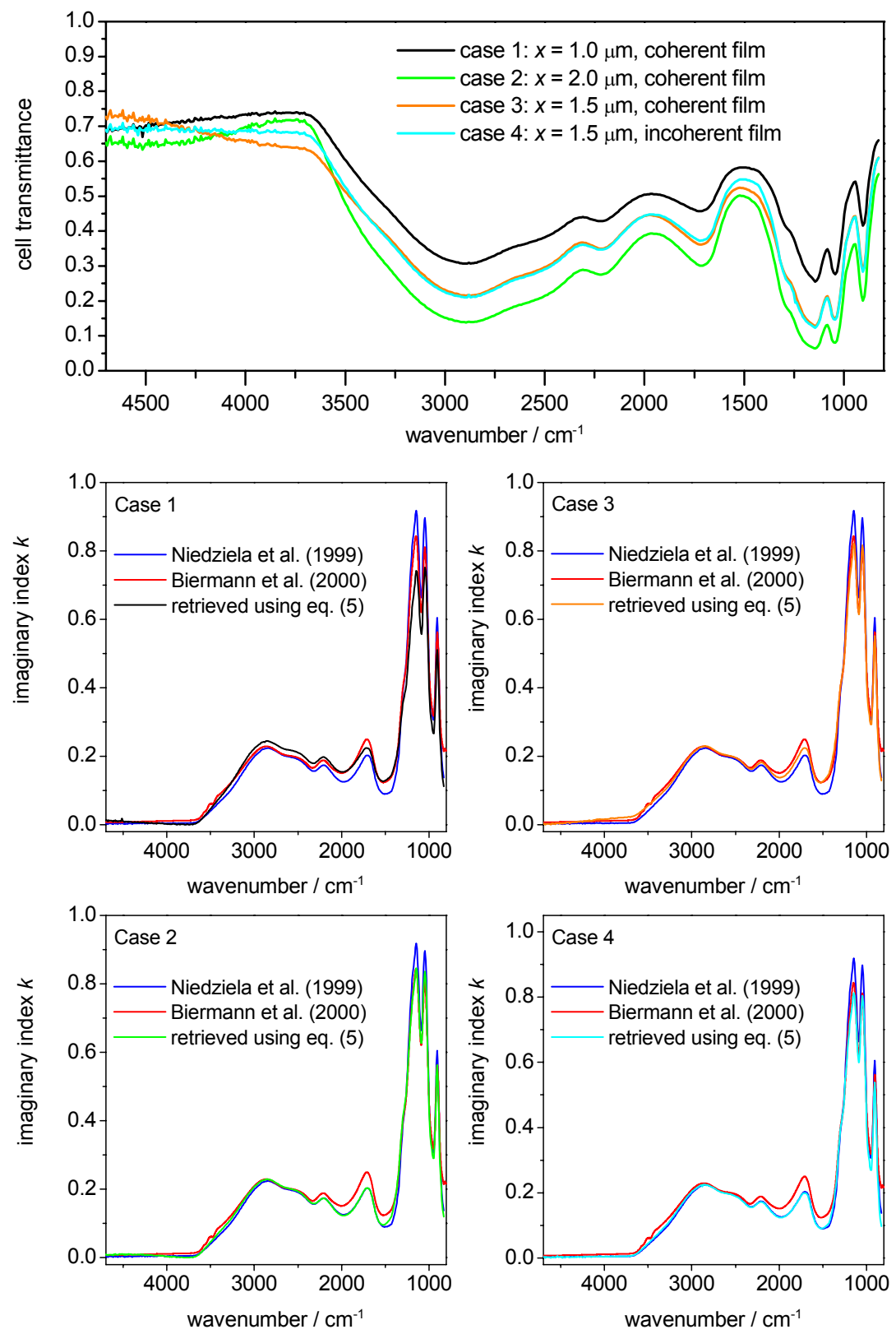

Fig. 7. Light transmittance through a sulphuric acid film $\left(80 \mathrm{wt} \% \mathrm{H}_{2} \mathrm{SO}_{4}, 240 \mathrm{~K}\right)$ sandwiched between two $\mathrm{AgBr}$ windows according to the cell model described in Appendix A. Top: transmittance through films of varying thicknesses $x$. Bottom: $k$ values derived from the cell transmittance by using Eq. (5) in comparison with the Niedziela et al. (1999) $k(\tilde{v})$ spectrum used to calculate the transmittance spectra and the corresponding Biermann et al. (2000) data set for $80 \mathrm{wt} \% \mathrm{H}_{2} \mathrm{SO}_{4}, 240 \mathrm{~K}$.

when applying the correct cell model for the light transmission deviate from the results using Eq. (5) by more than $20 \%$ in some frequency regions.

In order to elucidate whether the simplified treatment of light transmission by Eq. (5) explains some of the deviations of the Biermann et al. (2000) data set of optical constants, we performed some test calculations as follows. Based on the matrix formalism described by Heavens (1991), we calculated the exact light transmission through sulphuric acid films sandwiched between two $\mathrm{AgBr}$ windows, considering reflection losses at the air $/ \mathrm{AgBr}$ and $\mathrm{AgBr} / \mathrm{H}_{2} \mathrm{SO}_{4}$ interfaces. The calculations were performed for various film thicknesses between 1 and $2 \mu \mathrm{m}$ (i.e. the range covered in the work of Biermann et al., 2000) using alternatively the $\mathrm{H}_{2} \mathrm{SO}_{4} / \mathrm{H}_{2} \mathrm{O}$ optical constants of Niedziela et al. (1999) and Myhre et al. (2003) as input values. These simulated transmission spectra were then analysed in terms of Eq. (5) yielding the imaginary index $k$ as a result of the Biermann et al. (2000) data analysis 
procedure, which then can be compared to the $k$ values of Niedziela et al. (1999) or Myhre et al. (2003) originally used to calculate the transmission spectra. The reader is referred to Appendix A for a thorough description of the theoretical basis for the model calculations. Figure 7 shows an exemplary result for sulphuric acid droplets of $80 \mathrm{wt} \% \mathrm{H}_{2} \mathrm{SO}_{4}$ at $240 \mathrm{~K}$. The top section of the figure shows the calculated transmittance for $\mathrm{H}_{2} \mathrm{SO}_{4} / \mathrm{H}_{2} \mathrm{O}$ films of different thicknesses (case 1: $x=1.0 \mu \mathrm{m}$, case 2: $x=2 \mu \mathrm{m}$, case 3 and $4: x=1.5 \mu \mathrm{m}$ ). Calculations 1-3 were performed by explicitly taking into account phase and amplitude of the light in the thin films resulting in an interference pattern most pronounced in the spectral regions of negligible absorption, i.e. at wavenumbers $>3600 \mathrm{~cm}^{-1}$. As a comparison, calculation 4 shows the light transmission assuming an incoherent film. In all cases it was assumed that coherence of the light is not maintained as the light passes the $\mathrm{AgBr}$ cell windows. In the bottom section of Fig. 7 are compared: (a) the imaginary index of the Niedziela et al. (1999) data set used to calculate the transmission spectra in the top section, (b) the corresponding Biermann et al. (2000) $k$ data set for $80 \mathrm{wt} \% \mathrm{H}_{2} \mathrm{SO}_{4}$ at $240 \mathrm{~K}$, and (c) the $k$ values derived from the cell transmittance by simply applying Eq. (5). For clarity, these plots are shown in separate graph windows for each simulation.

Biermann et al. (2000) stated that some uncertainty of their data is caused by their need to calibrate the film thickness using tabulated optical constants of sulphuric acid at room temperature published by Palmer and Williams (1975). However, as also noted by the authors, in their approach a calibration error in the film thickness would only lead to a linear scaling error of their $k(\tilde{v})$ spectrum. When comparing the Biermann et al. (2000) and Niedziela et al. (1999) $k(\tilde{v})$ spectra for $80 \mathrm{wt} \% \mathrm{H}_{2} \mathrm{SO}_{4}$ at $240 \mathrm{~K}$, there are spectral regions where the imaginary indices of Biermann et al. (2000) are much higher than the corresponding values determined by Niedziela et al. (1999) (especially between 2200 and $1300 \mathrm{~cm}^{-1}$ ), whereas the opposite behaviour is evident in the $\mathrm{HSO}_{4}^{-} / \mathrm{SO}_{4}^{2-}$ extinction regime. So this inconsistency cannot simply be accounted for by an incorrectly calibrated film thickness. But it is interesting to note, that exactly these spectral differences are the result of the simplified analysis of the cell transmittance when using Eq. (5). Especially in case 3 there is an excellent agreement between the original Biermann et al. (2000) $k(\tilde{v})$ spectrum and the $k$ values which are obtained when the Biermann et al. (2000) approach is applied to the theoretical cell transmittance spectrum calculated with the optical constants of Niedziela et al. (1999), including interference effects. Another example is presented in Fig. 8, this time using the Myhre et al. (2003) $n$ and $k$ data set for $58 \mathrm{wt} \% \mathrm{H}_{2} \mathrm{SO}_{4}(233 \mathrm{~K})$ to calculate the thin film transmission spectra. Here the Biermann et al. (2000) $k$ data are closely matched by the retrieved $k(\tilde{v})$ spectrum for $x=1.2 \mu \mathrm{m}$ (case 2 ). Hence we strongly suggest that the deviations between the different data sets of optical constants can be at least partly traced back to the simplified data anal- ysis approach employed by Biermann et al. (2000) to extract optical constants from their thin film measurements.

\subsection{The $\mathrm{HNO}_{3} / \mathrm{H}_{2} \mathrm{O}$ system}

When using the Norman et al. (1999) data set of optical constants to fit the extinction spectra of supercooled nitric acid droplets measured in the AIDA chamber (cases 4 and 5, Fig. 4), the experimental spectra are for the most part nicely reproduced by the Mie calculations. Table 1 shows that in case 4, the retrieved aerosol parameters (composition and nitrate mass concentration) agree very well with the measured ones, whereas in case 5 the nitrate mass concentration and the $\mathrm{HNO}_{3}$ concentration seem to be overestimated. However, we cannot exclude that the filter technique underestimates $\mathrm{m}$ (nitrate) due to sampling losses in the inlet tube. This assumption is supported by the fact that when using the retrieved nitrate mass concentration of $480 \mu \mathrm{g} / \mathrm{m}^{3}$ as input for the AIM model, an aerosol composition of $55 \mathrm{wt} \% \mathrm{HNO}_{3}$ is obtained which closely fits the value retrieved from the analysis of the FTIR extinction spectrum. In spite of the good agreement between measured and retrieved aerosol parameters, it has to be stated that the overall accuracy of the Mie fits is not as satisfactory as for the sulphuric acid spectra fitted with the Niedziela et al. (1999) data set of optical constants. Pronounced deviations occur in the $1700 \mathrm{~cm}^{-1}$ frequency region, covering the features from the $v_{2}$ mode of $\mathrm{H}_{2} \mathrm{O}$ at $1640 \mathrm{~cm}^{-1}$, the $v_{2}$ mode of $\mathrm{HNO}_{3}$ at $1672 \mathrm{~cm}^{-1}$, and the $v_{4}$ mode of $\mathrm{H}_{3} \mathrm{O}^{+}$at $1742 \mathrm{~cm}^{-1}$ (Querry and Tyler, 1980). In both cases, the spectra calculated with the Norman et al. (1999) data set significantly overestimate the extinction at $1672 \mathrm{~cm}^{-1}$. An explanation for this discrepancy might be that cooling from $220 \mathrm{~K}$ (the temperature where the optical constants were determined) down to $195 \mathrm{~K}$ (the actual AIDA temperature) further promotes the conversion of $\mathrm{HNO}_{3}$ into nitrate and hydronium ions. On the other hand, the authors have stated in their recent paper that the temperature dependence of the optical constants should be unimportant over the range $190-220 \mathrm{~K}$ at these acid concentrations (Norman et al., 2002). Furthermore, Koehler et al. (1992) recorded a FTIR spectrum of a liquid $53 \mathrm{wt} \%$ nitric acid solution at around $223 \mathrm{~K}$ (see spectrum d in Fig. 3 of their publication, composition similar to case 5 of this study), showing a band shape in the $1700 \mathrm{~cm}^{-1}$ frequency regime similar to our aerosol spectrum measured at $195 \mathrm{~K}$.

In addition to the spectral differences in the $1700 \mathrm{~cm}^{-1}$ frequency region, for which no reasonable explanation can be given at this place, there is also a slight spectral mismatch in the range from 2500 to $3600 \mathrm{~cm}^{-1}$, where extinction features from $\mathrm{H}_{2} \mathrm{O}$ and $\mathrm{H}_{3} \mathrm{O}^{+}$dominate (Querry and Tyler, 1980). Clearly, the overall results of the retrieval algorithms are not affected by these small spectral differences. Nonetheless, we believe that the slightly poorer performance of the $\mathrm{HNO}_{3} / \mathrm{H}_{2} \mathrm{O}$ optical constants is at least partly a consequence of the modified approach employed by Norman et al. (1999) 

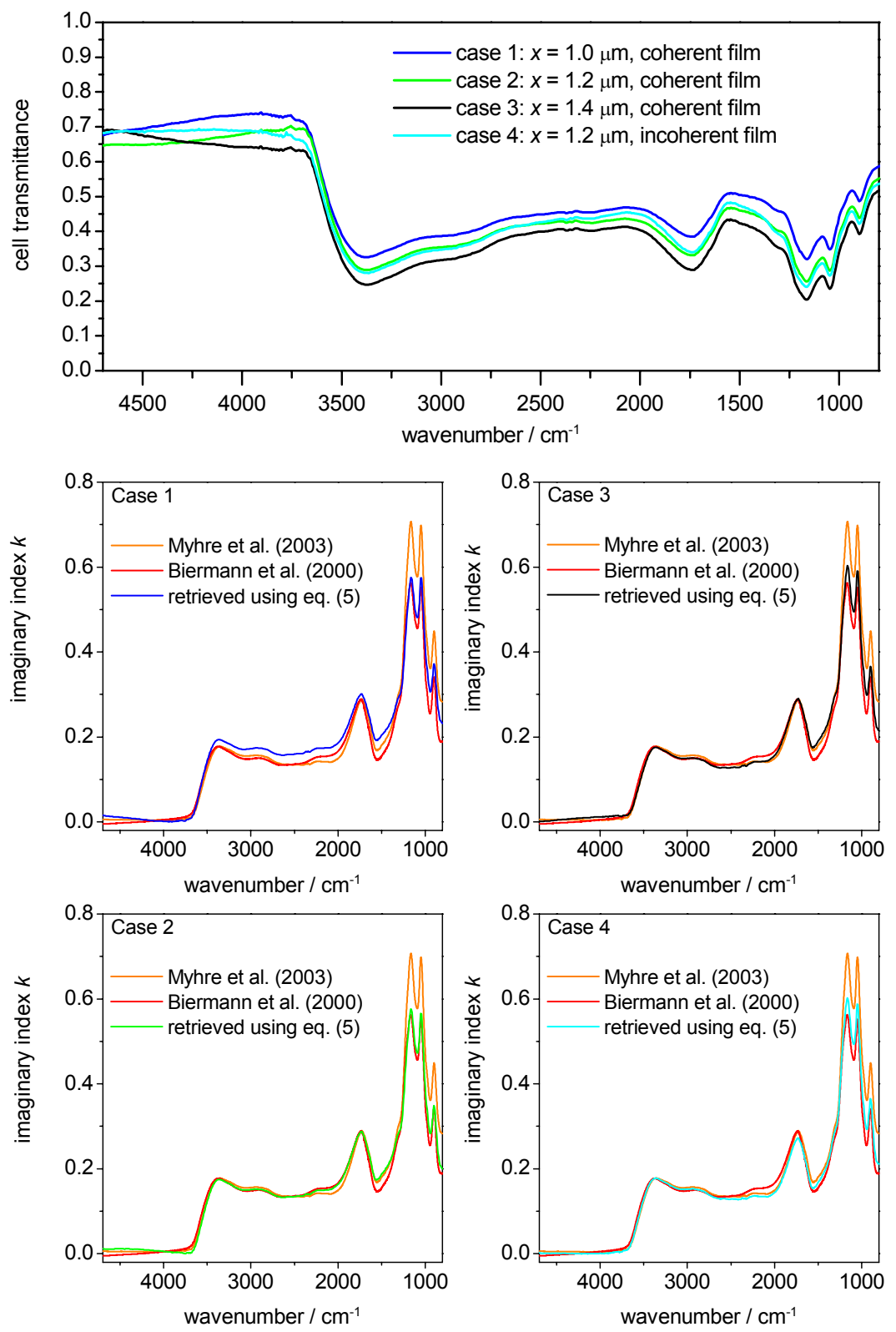

Fig. 8. Light transmittance through a sulphuric acid film $\left(58 \mathrm{wt} \% \mathrm{H}_{2} \mathrm{SO}_{4}, 233 \mathrm{~K}\right)$ sandwiched between two $\mathrm{AgBr}$ windows according to the cell model described in Appendix A. Top: Transmittance through films of varying thicknesses $x$. Bottom: $k$ values derived from the cell transmittance by using Eq. (5) in comparison with the Myhre et al. (2003) $k(\tilde{v})$ spectrum used to calculate the transmittance spectra and the corresponding Biermann et al. (2000) data set for $58 \mathrm{wt} \% \mathrm{H}_{2} \mathrm{SO}_{4}, 233 \mathrm{~K}$.

to analyse their aerosol extinction spectra in comparison with the Niedziela et al. (1999) study. Before addressing this aspect, we want to state that a much poorer agreement between experimental and Mie calculated spectra (case 4) is obtained when using the Biermann et al. (2000) data set of optical constants for $\mathrm{HNO}_{3} / \mathrm{H}_{2} \mathrm{O}$, except from the $1700 \mathrm{~cm}^{-1}$ extinction feature which is better reproduced than by the Norman data. As in the case of the $\mathrm{H}_{2} \mathrm{SO}_{4} / \mathrm{H}_{2} \mathrm{O}$ system, some of the discrepancies between the two data sets of $\mathrm{HNO}_{3} / \mathrm{H}_{2} \mathrm{O}$ optical constants may be traced back to the simplified Biermann et al. (2000) data analysis. Figure 9 (top) compares the Biermann et al. (2000) and Norman et al. (1999) $k(\tilde{v})$ spectra for $35 \mathrm{wt} \% \mathrm{HNO}_{3}$ at $220 \mathrm{~K}$. Once again, characteristic deviations of the Biermann et al. (2000) data from those of Norman et al. (1999) are evident, e.g. higher $k$ values in the $2000-1500 \mathrm{~cm}^{-1}$ range as well as lower $k$ values in the nitrate extinction regime at around $1300 \mathrm{~cm}^{-1}$. But in addition, there is a substantial disagreement between the $k(\tilde{v})$ 

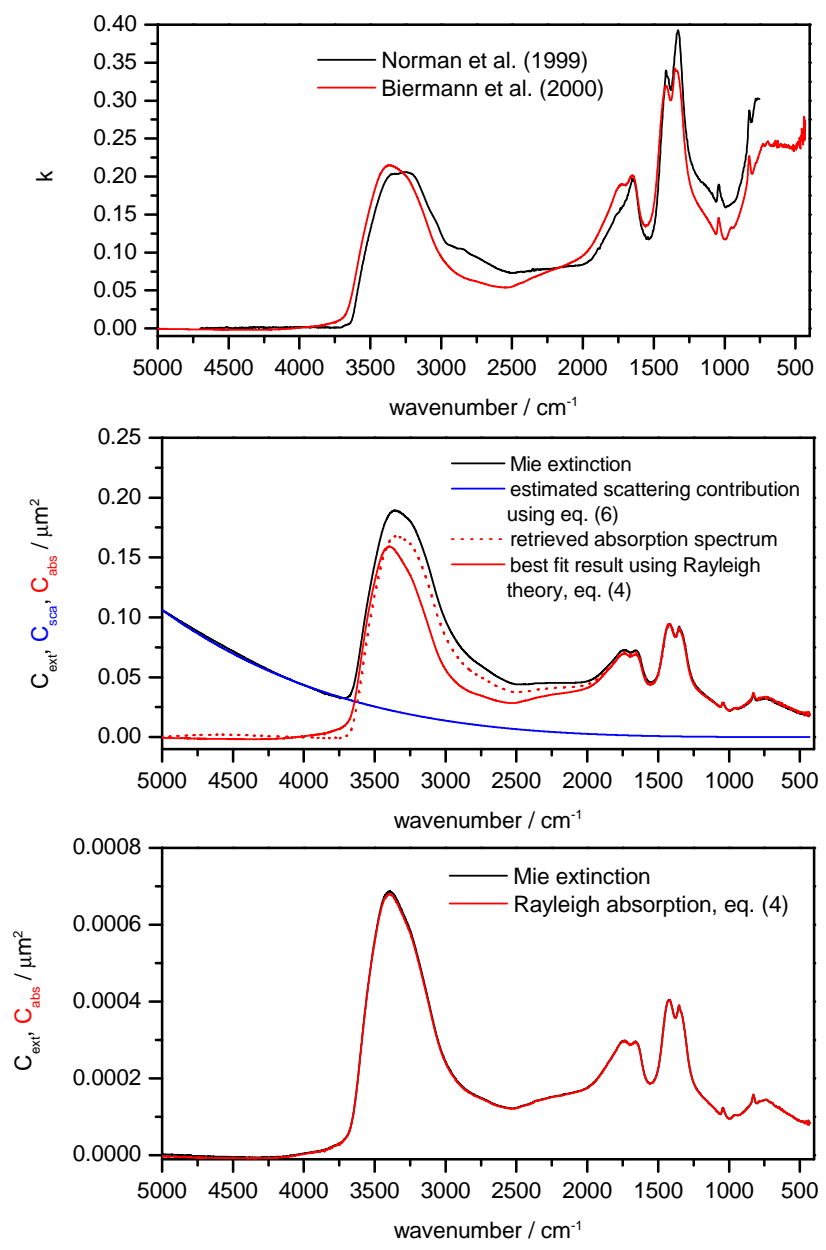

Fig. 9. Analysis of $\mathrm{HNO}_{3} / \mathrm{H}_{2} \mathrm{O}$ extinction spectra employing the Norman et al. (1999) approach. Top: comparison of the $k(\tilde{v})$ spectra from Norman et al. (1999) and Biermann et al. (2000) for $35 \mathrm{wt} \% \mathrm{HNO}_{3}$ at $220 \mathrm{~K}$. Middle: comparison of the absorption spectrum retrieved by subtracting an estimated scattering contribution from the Mie extinction spectrum with the best fit result using the Rayleigh absorption formula, Eq. (4). The calculations were performed for $35 \mathrm{wt} \% \mathrm{HNO}_{3}$ at $220 \mathrm{~K}$ using the Biermann et al. (2000) data set of optical constants $\left(C M D=0.6 \mu \mathrm{m}, \sigma_{g}=1.4\right)$. Bottom: comparison of Mie extinction and Rayleigh absorption for small size nitric acid droplets $\left(C M D=0.1 \mu \mathrm{m}, \sigma_{g}=1.4\right)$.

spectra in the wavenumber range from 2500 to $3600 \mathrm{~cm}^{-1}$, which cannot be attributed to the simplified analysis of the thin film spectra of Biermann et al. (2000).

To account for these differences, we want to briefly consider the Norman et al. (1999) method to derive optical constants from their aerosol extinction spectra. In their study dealing with the optical constants of the $\mathrm{H}_{2} \mathrm{SO}_{4} / \mathrm{H}_{2} \mathrm{O}$ system, Niedziela et al. (1999) had been able to record truly non-scattering aerosol spectra. However, the initial spectra of the smallest nitric acid droplets that Norman et al. (1999) were able to generate, still contained a significant scattering contribution at higher wavenumbers. Therefore, the authors subtracted this scattering contribution $I(v)$ from their extinction spectra assuming frequency-independent polarisability

$I(v)=\alpha v^{4}$,

where $\alpha$ is a scaling factor chosen to fit the experimental spectrum at high frequencies. The remaining absorption spectrum was then analysed in the same manner as in the Niedziela et al. (1999) approach. The authors claimed that the accuracy of the refractive indices for nitric acid droplets is $\pm 3 \%$, i.e. the same as in their previous $\mathrm{H}_{2} \mathrm{SO}_{4} / \mathrm{H}_{2} \mathrm{O}$ study. Now let us suppose that we would analyse the remaining absorption spectrum (after the subtraction of the scattering contribution) by means of the Ossenkopf et al. (1992) approach. This will only lead to an accurate $n$ and $k$ data set provided that the approximated absorption spectrum can still be accurately described by Rayleigh theory (i.e. by Eq. 4). Figure 9 (middle) shows a Mie calculation for "small" nitric acid droplets (35 wt $\% \mathrm{HNO}_{3}$, this time using the Biermann et al. (2000) data set of optical constants as input) with a count median diameter of $0.6 \mu \mathrm{m}$ and $\sigma_{g}=1.4$. Norman et al. (1999) reported that they generated "small" aerosol particles in the diameter range of $0.4-1 \mu \mathrm{m}$ whose FTIR spectra were then analysed as described above. Also shown in this plot is the absorption spectrum obtained by subtracting the scattering component $I(v)$ from the extinction spectrum assuming Eq. (6) to be valid. This spectrum is then fitted with an absorption spectrum calculated from Rayleigh theory using Eq. (4). Obviously, the retrieved absorption spectrum is not well reproduced by the Rayleigh fit. Especially the shape of the broad $\mathrm{OH}$ absorption feature centred at around $3300 \mathrm{~cm}^{-1}$ is not matched. For comparison, on the bottom of Fig. 9 Rayleigh and Mie calculations are shown for nitric acid droplets with a count median diameter of $0.1 \mu \mathrm{m}$. The close correspondence between the two spectra clearly validates the use of Eq. (4) to analyse truly non-scattering aerosol extinction spectra as in the $\mathrm{H}_{2} \mathrm{SO}_{4} / \mathrm{H}_{2} \mathrm{O}$ study by Niedziela et al. (1999). Although it is difficult to quantitatively assess the inaccuracy of the retrieved $\mathrm{HNO}_{3} / \mathrm{H}_{2} \mathrm{O}$ optical constants, we believe that the simplified subtraction of the scattering contribution by using Eq. (6) might explain the small spectral mismatch between our experimental FTIR spectra of nitric acid droplets and those calculated with the data set of optical constants by Norman et al. (1999) in the wavenumber range from 2500 to $3600 \mathrm{~cm}^{-1}$ as well as the differences between the Norman et al. (1999) and Biermann et al. (2000) $k(\tilde{v})$ spectra in this wavenumber regime.

\section{Conclusions and outlook}

FTIR extinction spectra of supercooled binary $\mathrm{H}_{2} \mathrm{SO}_{4} / \mathrm{H}_{2} \mathrm{O}$ and $\mathrm{HNO}_{3} / \mathrm{H}_{2} \mathrm{O}$ aerosols were quantitatively analysed in terms of aerosol composition and mass concentration using Mie theory with different laboratory data sets of optical 
constants as input values. Close agreement between retrieved and independently measured aerosol parameters was found when using the Niedziela et al. (1999) data set for the $\mathrm{H}_{2} \mathrm{SO}_{4} / \mathrm{H}_{2} \mathrm{O}$ system and the Norman et al. (1999) data set for $\mathrm{HNO}_{3} / \mathrm{H}_{2} \mathrm{O}$ aerosols. In the sulphuric acid system, the experimental FTIR spectra were excellently reproduced by the Mie calculations. Minor spectral differences occurred in the nitric acid system presumably due to the fact that the smallparticle spectra initially used by Norman et al. (1999) to extract the optical constants still contained a significant scattering contribution. When using the Biermann et al. (2000) data base of optical constants, the measured infrared spectra were only poorly reproduced by the Mie fits, especially in the wavenumber regime $1500-1000 \mathrm{~cm}^{-1}$. It was shown that the simplified analysis of their thin film spectra, i.e. neglecting multiple reflections at the air/window and window/thin film boundaries, might explain some of the differences between their data sets and those measured by Niedziela et al. (1999) and Norman et al. (1999). The quality of the Tisdale et al. (1998) and Myhre et al. (2003) data could not be ultimately assessed, as some of the deviations between measured and calculated extinction spectra might be explained by the fact that the actual AIDA temperature differed significantly from the temperature for which the adopted optical constants had been determined.

Clearly, the present results point the way to future studies dealing with supercooled ternary $\mathrm{H}_{2} \mathrm{SO}_{4} / \mathrm{H}_{2} \mathrm{O} / \mathrm{HNO}_{3}$ solution (STS) droplets, representing type Ib PSC particles. So far, only the mixing scheme developed by Biermann et al. (2000) permits the calculation of optical constants in the STS system which cover a broad range of compositions and temperatures. However, as recently shown by McPheat et al. (2002) on the basis of a measured extinction spectrum of STS aerosols of approximately $21 \mathrm{wt} \% \mathrm{H}_{2} \mathrm{SO}_{4}$ and $12 \mathrm{wt} \% \mathrm{HNO}_{3}$ at around $182 \mathrm{~K}$, the Mie calculation using the Biermann et al. (2000) optical constants differed significantly from the experimental spectrum in the important $750-1300 \mathrm{~cm}^{-1}$ region. They proposed that the temperature dependence of the sulphate feature in this regime might explain the poor Mie fit, since the $\mathrm{H}_{2} \mathrm{SO}_{4} / \mathrm{H}_{2} \mathrm{O}$ binary optical constants needed in the mixing scheme to calculate the ternary refractive indices were only measured down to $253 \mathrm{~K}$. But note that the calculation of the ternary refractive indices of STS particles with $21 \mathrm{wt} \% \mathrm{H}_{2} \mathrm{SO}_{4}$ and $12 \mathrm{wt} \% \mathrm{HNO}_{3}$ using the Biermann et al. (2000) mixing rule does not require optical constants for a binary solution containing $21 \mathrm{wt} \% \mathrm{H}_{2} \mathrm{SO}_{4}$ (which were in fact only measured down to $253 \mathrm{~K}$ ), but for a binary solution containing $33 \mathrm{wt} \% \mathrm{H}_{2} \mathrm{SO}_{4}$ (corresponding to $21 \mathrm{wt} \%$ $\mathrm{H}_{2} \mathrm{SO}_{4}+12 \mathrm{wt} \% \mathrm{HNO}_{3}$ in the ternary STS particles) which is accessible down to $193 \mathrm{~K}$ in the data base of Biermann et al. (2000). Rather we suggest that the generally poor quality of the data sets for binary solutions in this frequency region could be responsible for the observed spectral mismatch.

In view of the problems with the Biermann et al. (2000) data sets, Norman et al. (2002) used the mixing rule of Bier-

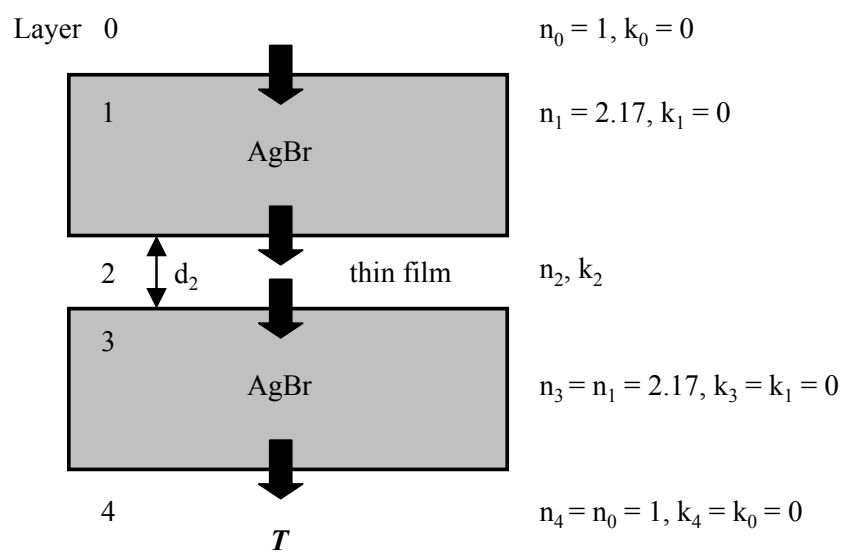

Fig. 10. Schematic of the absorption cell used in the Biermann et al. (2000) study, adopted from Rajaram et al. (2001).

mann et al. (2000) with the binary data sets of Niedziela et al. (1999) and Norman et al. (1999) to calculate the refractive indices of STS particles. They observed a better agreement with their measured optical constants compared to the values obtained when using the Biermann et al. (2000) binary data sets in the ternary calculations. Nevertheless, differences still remained which the authors traced back to deficiencies of the simple mixing model. As a result, they announced the publication of a modified model which should lead to quantitative agreement with their measured ternary refractive indices. Clearly, a quantitative test of these new optical constants by comparing retrieved STS aerosol compositions and mass concentrations with independent measurements - experiments for which the instrumentation of the AIDA aerosol chamber is ideally suited - is highly warranted.

\section{Appendix A}

Figure 10 shows a schematic of the absorption cell used in the thin film study of Biermann et al. (2000). According to the notation given by Heavens (1991), the cell transmittance $T$ through this four-layer system for the case of normal incidence is written as

$T=\frac{\left(t_{1} t_{2} t_{3} t_{4}\right)\left(t_{1}^{*} t_{2}^{*} t_{3}^{*} t_{4}^{*}\right)}{a a^{*}}$,

where $t_{m}$ is the Fresnel transmission coefficient for light crossing the $(m-1) \mid \mathrm{m}$ interface and $t_{m}^{*}$ is its complex conjugate. Defining $N_{m-1}=n_{m-1}-i k_{m-1}$ and $N_{m}=n_{m}-i k_{m}$ as the complex refractive indices of the $(m-1)^{t h}$ and $m^{t h}$ layer, the Fresnel coefficients for transmission $\left(t_{m}\right)$ and reflection $\left(r_{m}\right)$ can be calculated using

$$
\begin{aligned}
& r_{m}=g_{m}+i h_{m} \text { and } t_{m}=1+g_{m}+i h_{m}, \text { with } \\
& g_{m}=\frac{n_{m-1}^{2}+k_{m-1}^{2}-n_{m}^{2}-k_{m}^{2}}{\left(n_{m-1}+n_{m}\right)^{2}+\left(k_{m-1}+k_{m}\right)^{2}}
\end{aligned}
$$


$h_{m}=\frac{2\left(n_{m-1} k_{m}-n_{m} k_{m-1}\right)}{\left(n_{m-1}+n_{m}\right)^{2}+\left(k_{m-1}+k_{m}\right)^{2}}$.

The coefficient $a$ and its complex conjugate $a^{*}$ are obtained from the matrix product

$\left(\boldsymbol{C}_{\mathbf{1}}\right)\left(\boldsymbol{C}_{\mathbf{2}}\right)\left(\boldsymbol{C}_{\mathbf{3}}\right)\left(\boldsymbol{C}_{\mathbf{4}}\right)=\left(\begin{array}{ll}a & b \\ c & d\end{array}\right)$,

where each individual matrix is defined as

$\left(\boldsymbol{C}_{\boldsymbol{m}}\right)=\left(\begin{array}{cc}e^{i \delta_{m-1}} & r_{m} e^{i \delta_{m-1}} \\ r_{m} e^{-i \delta_{m-1}} & e^{-i \delta_{m-1}}\end{array}\right)$.

With $d_{m-1}$ denoting the thickness of the $(m-1)^{t h}$ layer, the phase term $\exp \left(i \delta_{m-1}\right)$ in the $m^{\text {th }}$ matrix is given by

$$
\begin{aligned}
\exp i \delta_{m-1}= & \exp \frac{2 \pi i}{\lambda}\left(n_{m-1}-i k_{m-1}\right) d_{m-1} \\
& =\exp \alpha_{m-1} \exp i \gamma_{m-1},
\end{aligned}
$$

with $\alpha_{m-1}=\frac{2 \pi}{\lambda} k_{m-1} d_{m-1}$ and $\gamma_{m-1}=\frac{2 \pi}{\lambda} n_{m-1} d_{m-1}$.

The refractive index of $\mathrm{AgBr}$ was taken from a handbook of optical constants (Palik, 1998). As there seems to be only a small variation of $n_{1}(\mathrm{AgBr})$ over the wavelength range of interest, a constant value of $n_{1}=2.17$ was employed in the calculations. The optical constants for the thin $\mathrm{H}_{2} \mathrm{SO}_{4} / \mathrm{H}_{2} \mathrm{O}$ films $\left(n_{2}, k_{2}\right)$ were extracted from the data base of Niedziela et al. (1999) and Myhre et al. (2003). As already mentioned in the main section, we assumed that the thicknessto-wavelength ratio is so large that phase coherence of the light beam is not maintained when crossing the $\mathrm{AgBr}$ windows. Therefore, it was necessary to average the phase term $\exp i \delta_{m-1}$ (equal to exp $i \gamma_{m-1}$ as $k_{m-1}=0$ ) in the matrices $\left(\boldsymbol{C}_{2}\right)$ and $\left(\boldsymbol{C}_{\mathbf{4}}\right)$ over a range of thicknesses $d_{m-1}$ to eliminate the interference pattern due to multiple reflections within the $\mathrm{AgBr}$ windows. Biermann et al. (2000) stated that the $\mathrm{AgBr}$ windows of their absorption cell were arranged in a highly parallel manner which should result in oscillations in their spectra owing to coherent interference as a result of multiple reflections within the sulphuric acid films. In some cases, these oscillations are clearly visible in their measured spectra at wavenumbers $>3600 \mathrm{~cm}^{-1}$ (see e.g. the absorption spectra of 30 and $65 \mathrm{wt} \% \mathrm{HNO}_{3} / \mathrm{H}_{2} \mathrm{O}$ solutions in Fig. 5 of their publication). As a comparison, we performed our calculations assuming coherent as well as incoherent thin films. In the latter case, an additional averaging process has to be introduced in the phase term of matrix $\left(\boldsymbol{C}_{\mathbf{3}}\right)$. For a given layer thickness $d_{2}$, the averaged transmittance was calculated analytically by averaging the imaginary part of the phase term $\exp i \delta_{2}$, that is $\exp i \gamma_{2}$, over a range of thicknesses $d_{2}$. To extract the $k(\tilde{v})$ spectrum from their transmission spectra by applying Eq. (5), Biermann et al. (2000) divided their cell transmittance spectrum through a reference spectrum of the empty cell. Obviously, reflection losses at the various interfaces of the absorption cell cannot be accounted for properly by this method because of the different refractive indices of the $\mathrm{H}_{2} \mathrm{SO}_{4} / \mathrm{H}_{2} \mathrm{O}$ films and air. Furthermore, in the wavenumber regions of negligible absorption $\left(>3600 \mathrm{~cm}^{-1}\right)$, the cell transmittance through sulphuric acid films is higher than the transmittance of the empty cell, so that by rigorously applying the Biermann et al. (2000) data analysis procedure, one would get negative $k$ values in this wavenumber regime. For example, the cell transmittance for $80 \mathrm{wt} \% \mathrm{H}_{2} \mathrm{SO}_{4}(240 \mathrm{~K})$ at $4500 \mathrm{~cm}^{-1}$ (where $n=1.385$ and $k=0.00348$ ) amounts to $T=0.695$, whereas the transmittance of the empty cell $(n=1$ and $k=0$ ) is $T=0.637$. Hence we believe that the authors must have scaled their empty cell transmittance spectrum to match the transmittance of the sulphuric acid films in the high frequency region. Thus, in our model calculations we divided the cell transmittance spectrum of the sulphuric acid films through a frequency-independent $I_{0}(\tilde{v})$ equal to the maximum transmittance in the sample spectrum. The resulting absorbance spectrum was then analysed by applying Eq. (5) yielding the $k(\tilde{v})$ spectrum as a result of the Biermann et al. (2000) data analysis procedure. Two examples of these calculations were presented in the main text (Figs. 7 and 8). Both calculations clearly point out the differences between the $k$ values originally used as input for the calculation of the cell transmittance and those obtained from the Biermann et al. (2000) approach.

Acknowledgements. We thank C. E. L. Myhre and M. Höpfner for useful discussions and we would like to acknowledge the continuous support by all members of the AIDA staff.

\section{References}

Bertram, A. K. and Sloan, J. J.: Temperature-dependent nucleation rate constants and freezing behavior of submicron nitric acid dihydrate aerosol particles under stratospheric conditions, J. Geophys. Res. (Atmos.), 103, 3553-3561, 1998.

Beyer, K. D., Ravishankara, A. R., and Lovejoy, E. R.: Measurements of UV refractive indices and densities of $\mathrm{H}_{2} \mathrm{SO}_{4} / \mathrm{H}_{2} \mathrm{O}$ and $\mathrm{H}_{2} \mathrm{SO}_{4} / \mathrm{HNO}_{3} / \mathrm{H}_{2} \mathrm{O}$ solutions, J. Geophys. Res. (Atmos.), 101, 14 519-14 524, 1996.

Biermann, U. M., Luo, B. P., and Peter, T.: Absorption spectra and optical constants of binary and ternary solutions of $\mathrm{H}_{2} \mathrm{SO}_{4}$, $\mathrm{HNO}_{3}$, and $\mathrm{H}_{2} \mathrm{O}$ in the mid infrared at atmospheric temperatures, J. Phys. Chem. A, 104, 783-793, 2000.

Bohren, C. F. and Huffman, D. R.: Absorption and Scattering of Light by Small Particles, John Wiley \& Sons, Inc., New York, 1983.

Carslaw, K. S., Clegg, S. L., and Brimblecombe, P.: A Thermodynamic Model of the System $\mathrm{HCl}-\mathrm{HNO}_{3}-\mathrm{H}_{2} \mathrm{SO}_{4}-\mathrm{H}_{2} \mathrm{O}$, Including Solubilities of $\mathrm{HBr}$, from $<200$ to $328 \mathrm{~K}$, J. Phys. Chem., 99, 11 557-11 574, 1995.

Clapp, M. L., Miller, R. E., and Worsnop, D. R.: FrequencyDependent Optical Constants of Water Ice Obtained Directly from Aerosol Extinction Spectra, J. Phys. Chem., 99, 63176326, 1995. 
Clegg, S. L., Brimblecombe, P., and Wexler, A. S.: Thermodynamic model of the system $\mathrm{H}^{+}-\mathrm{NH}_{4}^{+}-\mathrm{SO}_{4}^{2-}-\mathrm{NO}_{3}^{-}-\mathrm{H}_{2} \mathrm{O}$ at tropospheric temperatures, J. Phys. Chem. A, 102, 2137-2154, 1998.

Disselkamp, R. S., Anthony, S. E., Prenni, A. J., Onasch, T. B., and Tolbert, M. A.: Crystallization kinetics of nitric acid dihydrate aerosols, J. Phys. Chem., 100, 9127-9137, 1996.

Echle, G., von Clarmann, T., and Oelhaf, H.: Optical and microphysical parameters of the Mt. Pinatubo aerosol as determined from MIPAS-B mid-IR limb emission spectra, J. Geophys. Res. (Atmos.), 103, 19 193-19211, 1998.

Eldering, A., Irion, F. W., Chang, A. Y., Gunson, M. R., Mills, F. P., and Steele, H. M.: Vertical profiles of aerosol volume from high-spectral-resolution infrared transmission measurements, I. Methodology, Appl. Opt., 40, 3082-3091, 2001.

Goldan, P. D., Kuster, W. C., Albritton, D. L., Fehsenfeld, F. C., Connell, P. S., and Norton, R. B.: Calibration and Tests of the Filter-Collection Method for Measuring Clean-Air, Ambient Levels of Nitric Acid, Atmos. Environ., 17, 1355-1364, 1983.

Grainger, R. G., Lambert, A., Taylor, F. W., Remedios, J. J., Rodgers, C. D., Corney, M., and Kerridge, B. J.: Infrared Absorption by Volcanic Stratospheric Aerosols Observed by ISAMS, Geophys. Res. Lett., 20, 1283-1286, 1993.

Heathfield, A. E., Newnham, D. A., Ballard, J., Grainger, R. G., and Lambert, A.: Infrared and visible Fourier-transform spectra of sulfuric-acid-water aerosols at 230 and $294 \mathrm{~K}$, Appl. Opt., 38, 6408-6420, 1999.

Heavens, O. S.: Optical Properties of Thin Solid Films, Dover Publications, Inc., New York, 1991.

Hinds, W. C.: Aerosol Technology: Properties, Behavior, and Measurement of Airborne Particles, John Wiley \& Sons, Inc., New York, 1999.

Höpfner, M., Oelhaf, H., Wetzel, G., Friedl-Vallon, F., Kleinert, A., Lengel, A., Maucher, G., Nordmeyer, H., Glatthor, N., Stiller, G., von Clarmann, T., Fischer, H., Kröger, C., and Deshler, T.: Evidence of scattering of tropospheric radiation by PSCs in mid-IR limb emission spectra: MIPAS-B observations and KOPRA simulations, Geophys. Res. Lett., 29, 1278, doi: 10.1029/2001GL014443, 2002.

Höpfner, M.: Study on the impact of polar stratospheric clouds on high resolution mid-IR limb emission spectra, J. Quant. Spectrosc. Radiat. Transfer, doi: 10.1016/S0022-4073(02)00299-6, in press, 2003.

Koehler, B. G., Middlebrook, A. M., and Tolbert, M. A.: Characterization of Model Polar Stratospheric Cloud Films Using Fourier Transform Infrared Spectroscopy and Temperature Programmed Desorption, J. Geophys. Res. (Atmos.), 97, 8065-8074, 1992.

Lee, K. W., Chen, H., and Gieseke, J. A.: Log-Normally Preserving Size Distribution for Brownian Coagulation in the Free-Molecule Regime, Aerosol Sci. Tech., 3, 53-62, 1984.

McPheat, R. A., Bass, S. F., Newnham, D. A., Ballard, J., and Remedios, J. J.: Comparison of aerosol and thin film spectra of supercooled ternary solution aerosol, J. Geophys. Res. (Atmos.), 107, 4371, doi: 10.1029/2001JD000641, 2002.

Möhler, O., Stetzer, O., Schaefers, S., Linke, C., Schnaiter, M., Tiede, R., Saathoff, H., Krämer, M., Mangold, A., Budz, P., Zink, P., Schreiner, J., Mauersberger, K., Haag, W., Kärcher, B., and Schurath, U.: Experimental investigation of homogeneous freezing of sulphuric acid particles in the aerosol chamber AIDA, At- mos. Chem. Phys., 3, 211-223, 2003.

Myhre, C. E. L., Christensen, D. H., Nicolaisen, F. M., and Nielsen, C. J.: Spectroscopic Study of Aqueous $\mathrm{H}_{2} \mathrm{SO}_{4}$ at different Temperatures and Compositions: Variations in Dissociation and Optical Properties, J. Phys. Chem. A, doi: 10.1021/jp026576n, 2003.

Myhre, C. E. L., Nielsen, C. J., and Saastad, O. W.: Density and surface tension of aqueous $\mathrm{H}_{2} \mathrm{SO}_{4}$ at low temperature, J. Chem. Eng. Data, 43, 617-622, 1998.

Neuman, J. A., Huey, L. G., Ryerson, T. B., and Fahey, D. W.: Study of inlet materials for sampling atmospheric nitric acid, Environ. Sci. Technol., 33, 1133-1136, 1999.

Niedziela, R. F., Miller, R. E., and Worsnop, D. R.: Temperatureand frequency-dependent optical constants for nitric acid dihydrate from aerosol spectroscopy, J. Phys. Chem. A, 102, 64776484, 1998.

Niedziela, R. F., Norman, M. L., DeForest, C. L., Miller, R. E., and Worsnop, D. R.: A temperature- and composition-dependent study of $\mathrm{H}_{2} \mathrm{SO}_{4}$ aerosol optical constants using Fourier transform and tunable diode laser infrared spectroscopy, J. Phys. Chem. A, 103, 8030-8040, 1999.

Norman, M. L., Miller, R. E., and Worsnop, D. R.: Ternary $\mathrm{H}_{2} \mathrm{SO}_{4} / \mathrm{HNO}_{3} / \mathrm{H}_{2} \mathrm{O}$ optical constants: New measurements from aerosol spectroscopy under stratospheric conditions, J. Phys. Chem. A, 106, 6075-6083, 2002.

Norman, M. L., Qian, J., Miller, R. E., and Worsnop, D. R.: Infrared complex refractive indices of supercooled liquid $\mathrm{HNO}_{3} / \mathrm{H}_{2} \mathrm{O}$ aerosols, J. Geophys. Res. (Atmos.), 104, 30 571-30 584, 1999.

Ossenkopf, V., Henning, T., and Mathis, J. S.: Constraints on Cosmic Silicates, Astron. Astrophys., 261, 567-578, 1992.

Palik, E. D.: Handbook of Optical Constants of Solids III, Academic Press, San Diego, 1998.

Palmer, K. F. and Williams, D.: Optical constants of sulfuric acid; application to the clouds of Venus?, Appl. Opt., 14, 208-219, 1975.

Press, W. H., Teukolsky, S. A., Vetterling, W. T., and Flannery, B. P.: Numerical Recipes in C: The Art of Scientific Computing, Cambridge University Press, Cambridge, New York, Port Chester, Melbourne, Sidney, 1988, 1992.

Querry, M. R. and Tyler, I. L.: Reflectance and complex refractive indices in the infrared for aqueous solutions of nitric acid, J. Chem. Phys., 72, 2495-2499, 1980.

Rajaram, B., Glandorf, D. L., Curtis, D. B., Tolbert, M. A., Toon, O. B., and Ockman, N.: Temperature-dependent optical constants of water ice in the near infrared: new results and critical review of the available measurements, Appl. Opt., 40, 4449-4462, 2001.

Richwine, L. J., Clapp, M. L., Miller, R. E., and Worsnop, D. R.: Complex Refractive Indexes in the Infrared of Nitric Acid Trihydrate Aerosols, Geophys. Res. Lett., 22, 2625-2628, 1995.

Sasano, Y., Suzuki, M., Yokota, T., and Kanzawa, H.: Improved Limb Atmospheric Spectrometer (ILAS) for stratospheric ozone layer measurements by solar occultation technique, Geophys. Res. Lett., 26, 197-200, 1999.

Tabazadeh, A., Toon, O. B., Clegg, S. L., and Hamill, P.: A new parameterization of $\mathrm{H}_{2} \mathrm{SO}_{4} / \mathrm{H}_{2} \mathrm{O}$ aerosol composition: Atmospheric implications, Geophys. Res. Lett., 24, 1931-1934, 1997.

Tisdale, R. T., Glandorf, D. L., Tolbert, M. A., and Toon, O. B.: Infrared optical constants of low-temperature $\mathrm{H}_{2} \mathrm{SO}_{4}$ solutions representative of stratospheric sulfate aerosols, J. Geophys. Res. (Atmos.), 103, 25 353-25 370, 1998. 
Zöger, M., Afchine, A., Eicke, N., Gerhards, M.-T., Klein, E., McKenna, D. S., Mörschel, U., Schmidt, U., Tan, V., Tuitjer, F., Woyke, T., and Schiller, C.: Fast in situ stratospheric hygrometers: A new family of balloon-borne and airborne Lyman- $\alpha$ photofragment fluorescence hygrometers, J. Geophys. Res. (Atmos.), 104, 1807-1816, 1999. 